Chapter 3

\title{
Silk Fiber - Molecular Formation Mechanism, Structure- Property Relationship and Advanced Applications
}

\author{
Xinfang Liu and Ke-Qin Zhang \\ Additional information is available at the end of the chapter \\ http://dx.doi.org/10.5772/57611
}

\section{Introduction}

Silk fibers spun by several species of arthropods have existed naturally for hundreds of millions of years. The ecological functions of the silk fibers are closely related to their properties. For example, orb-weaving spiders produce a variety of different silks with diverse properties, each tailored to achieve a certain task (Figure 1) [1]. Most arthropod species produce silks used for building structures to capture prey and protect their offspring against environmental hazards [2]. The most investigated categories that have piqued the greatest amount of interest are spider silk and dragline silk in particular, produced by major ampullate glands and the cocoon silk of Bombyx mori (B. mori). The ongoing evolutionary optimization of silks from silkworms and spiders exhibit outstanding mechanical properties, such as strength and extensibility, as well as toughness, which outperform most other natural and man-made silk fibers (Table 1) [3, 4]. Due to its smooth texture, luster and strength, silks from natural silkworms have been extensively used in apparel and fashion applications for thousands of years [5]. Silks from spiders have also been utilized throughout history, such as sutures and fishing equipment in ancient Greece and Australasia.

In contrast petrochemical-based synthetic polymers commonly used today, such as polyethylene, which is formed by polymerization of ethylene at high temperature and pressure, or under the presence of some metal-based catalysis, B. mori and spider spin fibers from a highly concentrated, water-based protein solution under mild conditions [6, 7]. Due to current trends in exploration of natural biological materials and the demand for environmentally friendly (green) materials, investigation of the applications of silk fibers has steadily gained prominence. Silk fibers are emerging as candidates for applications in even non-apparel areas due in part to recognition for their extraordinary mechanical properties, as well as their biocompatibility and biodegradability. Currently, the promotion of silkworm as bio-factory to 
produce silk fibers fitting for innovative and advanced functional biological applications is a big trend. Compared to silkworm silks, the potential commercial applications for many spider silks are still extremely finite due to reasons such as difficulty of high-density spider farming, which is limited by the cannibalistic nature of most spiders. Additionally, only $\sim 12 \mathrm{~m}$ of silk can be obtained from a complete spider web, this is extremely small in comparison to the 600 to $900 \mathrm{~m}$ of silk that is yielded by one silkworm cocoon [8].

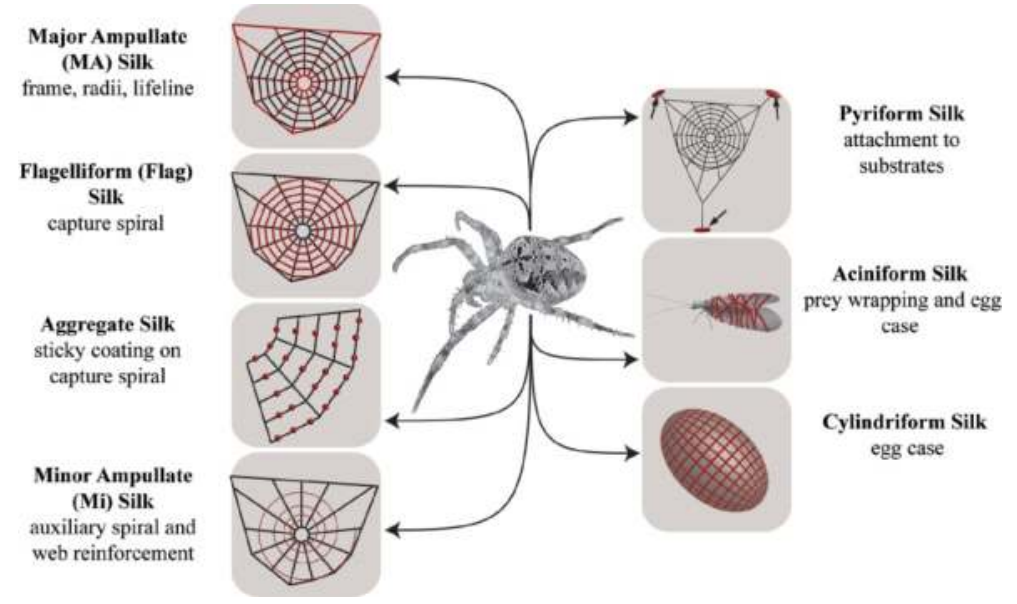

Figure 1. Schematic overview of different silk types produced by female orb-weaving spiders (Araneae). Each silk type (highlighted in red) is tailored for a specific purpose. (Reprinted from Ref. [1]. Copyright 2011, with permission from Elsevier.)

\begin{tabular}{lcccc}
\hline Fibers & Stiffness & Strength & Extensibility (\%) & Toughness \\
\hline B. mori cocoon silk & $\mathbf{( G P a )}$ & $\mathbf{( G P a )}$ & & $\mathbf{( M J \bullet \mathbf { m } ^ { - 3 } )}$ \\
B. mori reeled silk & 7 & 0.6 & 18 & 70 \\
A. Diadematus silk (dragline) & 15 & 0.7 & 28 & 150 \\
A. Diadematus silk (flagelliform) & 10 & 1.1 & 27 & 180 \\
Wool (at 100\% RH'b]) & 0.003 & 0.5 & 270 & 150 \\
Elastin & 0.5 & 0.2 & 5 & 60 \\
Nylon fiber & 0.001 & 0.002 & 15 & 2 \\
Kevlar 49 fiber & 5 & 0.95 & 2.7 & 80 \\
Carbon fiber & 130 & 306 & 1.3 & 50 \\
High-tensile steel & 300 & 4 & 0.8 & 25 \\
\hline
\end{tabular}

Table 1. Comparison of mechanical properties of natural silks and other synthetic fibers ${ }^{[a]}$. ([a] Data taken from refs. [3, 4]. [b] RH, relative humidity.) 
Artificial spinning is the most promising method of promoting the application of silk fibers, as it can output sufficient man-made fibers cost-effectively and with specific tailored properties. Remarkable efforts for silk fiber reproduction via reconstituted/recombinant silk fibroin are currently underway $[9,10]$. Reconstituted silk protein is derived from B. mori cocoons and the degummed B. mori silk fibers, they are soluble in concentrated $\mathrm{LiBr}$ aqueous solutions, yielding reconstituted silk protein solutions after dialysis [9]. Recent advances in transgenic technology enable the high level expression of recombinant proteins. Spider silk proteins have been produced by other organisms so that recombinant spider silk protein might be suitable for creation of artificial silk threads or other applications. Host organisms include bacteria, yeasts, animal cells and plants [3]. In order to biomimic native silks, the reconstituted or recombinant proteins used to spin artificial silks should possess amino acid similar to the ones found in native sites for sequence and composition. However, the properties of synthetic silk fibers currently do not meet the standards of native silks yet, as the composition, hierarchical structure and production conditions of natural silks all reportedly affect their mechanical properties [11]. Consequently, a profound knowledge of the natural formation process, chemical composition, relationships of structure and properties of silk fibers seems therefor imperative.

Thanks to recent developments in modern analytical techniques, significant progress has been made with respect to the structural characterization of silk. These techniques can provide molecular information about silk, including microscopic methods (atomic force microscopy (AFM), scanning and transmission electron microscopy (SEM and TEM), and scanning transmission x-ray microscopy (STXM)) and synchrotron x-ray diffraction (wide-angle x-ray diffraction (WAXD) and small-angle x-ray scattering (SAXS) combined with synchrotron radiation). Solid-state nuclear magnetic resonance (SS-NMR) is a powerful technique because it allows for the study of molecular structure and dynamics of semi-crystalline and amorphous materials. Raman and FTIR spectroscopy can provide the dominant conformational contents of a fiber. Raman microspectroscopy can be used to determine quantitative parameters characterizing the molecular structure (orientation and conformation, amino acid composition) of micrometer-sized biological samples. In this chapter, we will provide an overview of the current understanding of the silk fibers' structure taken advantage of these analytic methods, then describe in detail the structure-property relationships and the formation processes of silk fiber. Additionally, we will explore material morphologies and applications of these silk fibers.

\section{The structure-property relationship of silk fibers}

The structure-property relationship is one of the most intriguing 'mysteries' of silk fibers. Various studies have suggested that there is a strong connection between the structures of silk fibers and their physical (e. g., mechanical) properties. An understanding of the structureproperty relationship requires background knowledge of local structure, including the component and composition of silk fiber, the conformation and orientation of constitutive units with respect to the fiber, and so on. 


\subsection{The structure and composition of B. mori and spider dragline silk fibers}

In principle, the full range of properties of silk fibers can be calculated from their structural morphology and chemical composition. On the macroscopic level, the morphological structure of B. mori silk and spider dragline silk are very similar, as both possess a core-shell structure (Figure 2) [12]. The silk thread diameter varies across types and species. For example, coating the two core brins of $B$. mori silk fiber with sericin yields fibers about $20 \mu \mathrm{m}$ width. Spider dragline silks have a diameter of 3-5 $\mu \mathrm{m}$ and to date, have been described to contain only one protein monofilament.
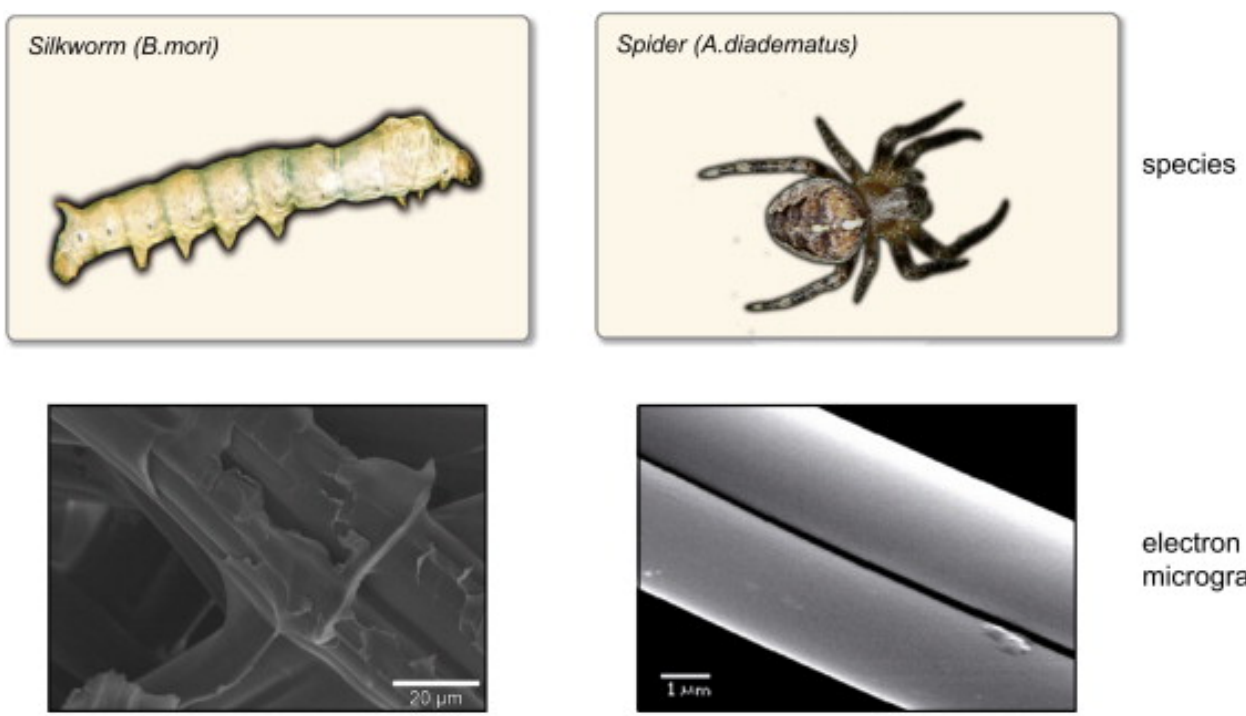

electron

micrograph
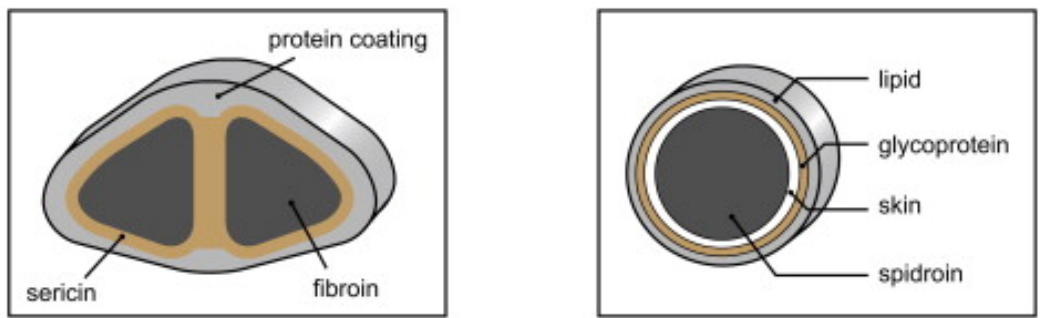

schematic

top view

Figure 2. Examples of silk fibers produced by silkworms and spiders and a schematic illustration. (Reprinted from Ref. [12]. Copyright 2008, with permission from Elsevier.)

Silk fibers are normally polyamino acid-based fibrous proteins. In contrast, the synthetic polymers, which are usually homopolymers or copolymers consisting of one or several simpler monomer, the biopolymers - silk fibers, the primary sequence and linkage between the 
monomers are arranged in a strictly controlled manner and are responsible for the formation of well-defined structure [13]. A range of microscopy methods, including SEM, TEM, and AFM, have been used to investigate the microstructure of silk fiber [14-19]. The results confirmed that silk fibers are composed of well-oriented bundles of nanofibrils. Generally, the coatings of silk fibers function as glue. The sericin coating, which occupies $25-30 \%$ of the weight of $B$. mori silk fiber, glues the two core brins together. However, recent studies have provided evidences that the coating may act as a fungicidal or bactericidal agent [20]. It may also have a role in the complex spinning process. Studies have demonstrated the presence of microvoids for both silk fibers [21, 22]. Microvoids are thought to develop during the final stages of the spinning process, in which viscous protein aqueous is stretched or loaded into the fibers.

As two major families of silk proteins, fibroin is the chief component of silkworm silk fiber, while spidroin (also named spider fibroin) is the analogue in spider silk fiber. The B. mori silk fibroin is composed of two protein chains, heavy-chain (H-fibroin) with the molecular weight of approximately $350 \mathrm{kDa}$ and light chain (L-fibroin, $\mathrm{M}_{\mathrm{w}} \sim 26 \mathrm{kDa}$ ) covalently linked by a disulfide bond at the carboxy-terminus of the two subunits [23-25] (Figure 3a). The main proteinaceous constituents of spider dragline silk are typically two major ampullate spidroins, MaSp1 and MaSp2, which are estimated to range from 250-350 kDa or larger [26-29]. A common feature of fibroins is the high content of alanine and glycine residues.

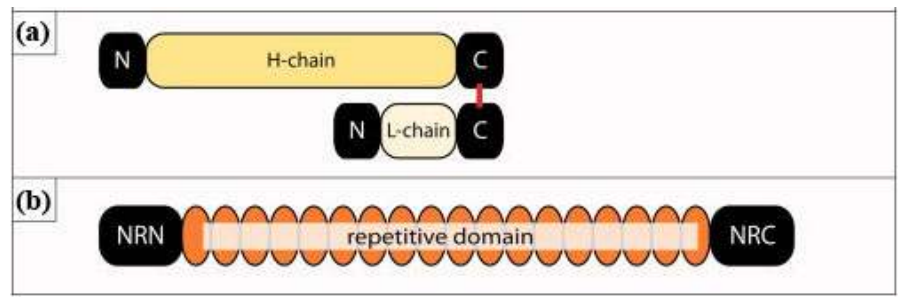

Figure 3. (a) Silkworm fibroin consisting of a covalently linked highly repetitive heavy and non-repetitive light chain. (b) Spider silk spidroins consist of a large repetitive core domain flanked by non-repetitive amino-(NRN) and carboxyterminal (NRC) domains. (Figure slightly modified with permission from Ref. [30]. Copyright 2011 Wiley Periodicals, Inc.)

\subsection{Hierarchical structure of fibroin in B. mori and spider silk fibers}

The primary sequence plays an important role in defining basic materials. Despite being quite different in their primary structure, B. mori fibroin heavy chain and spider spidroins share fundamental similarities. Both have large central core of repeated modular units (Figure 4), flanked by nonrepetitive amino- (NRN) [31, 32] and carboxy- (NRC) [29] terminal domains (Figure 3). The light chain of B. mori fibroin, has a standard amino acid composition and a nonrepeating sequence. It plays only a marginal role in the fiber [33]. The organization of the repeating modular units can differ significantly, as seen in the sequences of different protein types. As the major component of B. mori fibroin, the complete amino acid sequence of the $B$. mori fibroin heavy chain is composed of a highly repetitive 
(Gly-Ala) $)_{n}$ sequence motif and tyrosine-rich domains [34]. In MaSp1, the modular units mainly consist of a subset of the sequence motifs (Ala) $)_{n}$ followed by several GGX motifs, with $X$ representing a variable amino acid. In MaSp2, the GGX motif is replaced by the GPGXX motif, which contains more proline residues [26, 27]. The modular units are repeated up to several hundred times in the central core of B. mori fibroin heavy chain and spider spidroins such that they largely determine the macroscopic properties of the fibers. The highly conserved sequence of nonrepetitive amino- and carboxy- terminal domains are essential for fiber formation and expected to be of functional relevance [35-39]. Moreover, the analysis of the hydropathicity of these fibroins reveals a pair of hydrophobic and hydrophilic counterparts. The central region of the protein is mostly hydrophobic, while the nonrepetitive amino- and carboxy- terminal domains are more hydrophilic [40].

\title{
Bombyx mori fibroin:
}

GAGAGSGAGAGSGAGAGSGAGAGSGAGAGSGAGAGYGAGVGVGYGAGYGAGAG AGYGAGAGSGAASGAGAGSGAGAGSGAGAGSGAGAGSGAGAGSGAGAGSGAGA GSGAGAGSGAGAGSGAGAGSGAGVGSGAGAGSGAGAGVGYGAGAGVGYGAGAG SGAASGAGAGSGAGAGSGAGAGSGAGAGSGAGAGSGAGAGSGAGAGSGAGAGSG

\section{Nephila clavipes MaSp1: AAAAAAGGAGQGGYGGLGSQGAGRGGLGGQGAGAAAAAAGGAGQGGYGGLGG QGAGQGGYGGLGSQGAGRGGLGGQGAGAAAAAAA}

\section{Nephila clavipes MaSp2: AAAAAAAASGPGQQGPGGYGPGQQGPGGYGPGQQGPSGPGSAAAAAAAASGPGQ QGPGGYGPGQQGPGGYGPGQQGLSGPGSAAAAAAA}

\author{
Araneus diadematus MaSp1: \\ AAAAAAAAVGAGGGGQGGLGSGGAGQGYGAGLGGQGGASAAAAAAGGQGGQG \\ GQGGYGGLGSQGAGGAGQLGYGAGQESAAAAAAAA
}

\section{Araneus diadematus MaSp2: \\ AAAAAAGGYGPGSGQQGPSQQGPGQQGPGGQGPYGPGASAAAAAAGGYGPGSGQ QGPGGQGPYGPGSSAAAAAA}

Figure 4. Typical amino acid sequences of repetitive core of $B$. mori fibroin heavy chain, minor ampullate spidroins and major ampullate spidroins. The highly repetitive $(\mathrm{Gly}-\mathrm{Ala})_{n}$ and $(\mathrm{Ala})_{\mathrm{n}}$ sequence motifs are highlighted in red. The accession numbers for the sequences are P05790, P19837, P46804, AAC47009 and AAC47010 respectively.

The primary structural motifs have a preferred secondary structure and give rise to structures higher up the hierarchy. NMR, circular dichroism (CD), IR and Raman spectroscopy were usually used to examine the chemical, conformational, and orientational information of secondary structures for silk proteins [41-51]. There are three major conformations of silk proteins: the random coil, the $\alpha$-helix and the $\beta$-sheet [52-54]. Using the approach of Porter, and reducing the complex secondary structure of silk proteins into fractions of ordered and 
disordered material, they are roughly equivalent to crystalline and non-crystalline phase of silk proteins, respectively $[55,56]$.

The solid threads are characteristic of well-oriented $\beta$-sheet, the dominant secondary structure in silk fibers [57-59]. The first Raman spectrum of B. mori silk fiber has clearly shown the predominance of $\beta$-sheet, matching the results previously obtained from other techniques [60]. The total amount of $\beta$-sheet is around $50 \%$ for B. mori silk, which matched the proportion of the (Gly-Ala) motif $[42,43,46]$. Therefore, it is widely accepted that the $B$. mori fibroin is composed of a highly repetitive (Gly-Ala) $)_{n}$ sequence motif adopting antiparallel $\beta$-sheet conformation, namely silk II of the crystalline form. The $\beta$-sheet crystallite is the molecular network constructed by crosslinking $\beta$-sheet conformation of the molecular structures within several neighboring silk protein molecules [61]. It can be indexed as a monoclinic space group with a rectangular unit cell parameter of $a=0.938 \mathrm{~nm}, b=0.949 \mathrm{~nm}$ and $c=0.698 \mathrm{~nm}$ for B. mori silk [62]. Drummy et al. investigated B. mori silk fiber bundles using wide angle X-ray scattering (WAXS) [63]. The amorphous halo was also investigated from the WAXS pattern. The results concluded that silk fiber is made up of crystalline regions and connected by regions of amorphous or non-crystalline regions, each comprising of approximately $50 \%$ of the total structure. These features are in agreement with structural model proposed before [64].

It is quite firmly believed that the (Ala) ${ }_{\mathrm{n}}$ domains in spider dragline silk fibers adopt a $\beta$-sheet conformation, which are predominantly found to be antiparallel folding and organized into crystallite [41, 61, 65]. Based on the x-ray diffraction pattern, the $\beta$-sheet crystallites can be indexed as an orthogonal unit with cell parameters of $a=1.03 \mathrm{~nm}, b=0.944 \mathrm{~nm}$ and $c=0.695 \mathrm{~nm}$ for Nephila spider dragline silk [66]. From the data presented, the content of $\beta$-sheet conformation in Nephila spider dragline silks ranging from $30 \%$ to $40 \%[46,48]$. This value is much higher than the $20 \%$ average for degree of crystallinity (amount of $\beta$-sheet crystallites), as reported by XRD [67-69]. The lower crystallinity of spider dragline seems to closely correlate with less highly ordered $\beta$-sheet content for diffraction [61].

It is expected that the mechanical properties of silk fibers will critically depend on the characters of $\beta$-sheet crystallites, significant properties include crystallinity, size (aspect ratio, distribution) and dispersion of $\beta$-sheet crystallites, the intercrystallite distance, and the degree of orientation in the silk fiber. The size of $\beta$-sheet crystallite in B. mori silk fiber, determined via quantitative examination of the dark field TEM images, were revealed to be 20 to $170 \mathrm{~nm}$ in the axial direction and 1 to $20 \mathrm{~nm}$ in the lateral direction. And all the crystallites were uniformly distributed in the whole fiber matrix [14]. The smaller crystallite sizes, as measured from LVTEM and WAXS images, are a reasonable match to those calculated from Scherrer analysis of x-ray fiber pattern [63]. It has a large distribution of sizes range from only a few nanometers to tens of nanometers in length. The average crystallite size of Nephila spider dragline silks is calculated to be approximately $2 \times 5 \times 7 \mathrm{~nm}$ based on $X$-ray diffraction patterns of single and bundles of fiber [70]. The correlation lengths related to intercrystallite distance along the fiber axis is $\sim 13-18 \mathrm{~nm}$, measured from SAXS for Nephila spider dragline silk. This value is agreeable with the distance between the $\beta$-sheets from the MaSp1 sequence [19]. The quantitative determination of orientation of the secondary structure for silk protein molecules shows that the $\beta$-sheets are aligned parallel to the fiber axis [57] and the $\beta$-sheets crystallites 
representing the highly ordered fraction are well-oriented along the silk fiber [70-72]. Additionally, the $\beta$-sheets of $B$. mori silks are slightly better oriented than those of dragline silks, corresponding to the fact that they are more crystalline than spider dragline silk [46].

The non-crystalline regions are often described as amorphous, poorly orientated, or randomly coiled sections of the peptide. The structural organization in the amorphous phase is not well understood yet. The existence of $\beta$-turn or $\beta$-spiral and helical conformations has been suggested for amorphous domains $[42,46,65,73,74]$. Tyrosine residue, on average, may form distorted $\beta$-turns and distorted $\beta$-sheets, which is characterized by ${ }^{13} \mathrm{C}$ solid-state NMR in the amorphous matrix of $B$. mori silk $[42,75]$. The Gly-rich regions in spider dragline silk have been described as the amorphous rubber based on X-ray diffraction studies [76]. The precise structure of the GlyGlyX motif in MaSp1 has been somewhat controversial. Recent NMR studies provided evidence of the presence of less ordered helical type structure or distorted $\beta$-sheets adopted by the GlyGlyX motif $[48,73]$. However, for MaSp2, ADF 3 and 4 (the fibroin of major ampullate dragline silk for spider Araneus diadematus), the structure of the GlyProGlyXX repeat has been proposed to be a $\beta$-turns or spiral structure. The stability of these structures is given by the interchain hydrogen bonding [77]. The molecular chains in the amorphous phase are often considered to be randomly oriented. Studies from Raman [46] and SS-NMR [73] reported that the protein backbones in the amorphous regions of silk fibers are not randomly oriented but exhibit certain degree of orientation along the fiber axis, albeit much less oriented than $\beta$-sheet crystallites. Meanwhile, the higher level of orientation of the amorphous phase for the spider silks than that for B. mori silk.

Recent computational approaches have been useful in modeling nanostructure of silk. Molecular modeling integrated the information known about the structures, and has been used to characterize the nanostructure of the silk. Based on a bottom-up molecular computational approach using replica exchange molecular dynamic, Keten et al. reported atomic-level structures of MaSp1 and MaSp2 proteins from the Nephila Clavipes spider dragline silk sequence. It showed that poly-alanine segments in silk have an extremely high propensity for forming distinct and orderly $\beta$-sheet crystallites. Previous molecular dynamic simulations on poly-alanine aggregation also suggested that anti-parallel orientations in the hydrogen bonding direction and parallel stacking in the side - chain direction leads to stable $\beta$-sheets [78]. Glycine-rich regions are less orderly, predominantly forming helical type structures and $\beta$-turns in amorphous domains. The density of hydrogen bonds in amorphous regions is lower than in $\beta$-sheet crystallites $[79,80]$. All of the results are excellently consistent with available experiment evidence and may contribute towards an improved understanding of the source of silk's strength and toughness.

According to the prevalent characterizations mentioned above, silk fiber is considered a semicrystalline polymer with a hierarchical structure in which highly oriented $\beta$-sheets crystallites connecting with an amorphous matrix are organized in nanofibrils or fibrillar entities [81] (Figure 5). However, it has been proposed that there exists a third phase, or interphase consisting of weakly oriented $\beta$-sheets regions $[68,82-84]$ or oriented amorphous domains $[85,86]$ in silk. Recent NMR and IR studies performed on silk used hydrogendeuterium (H-D) exchange to differentiate among three structures. The data revealed that the 

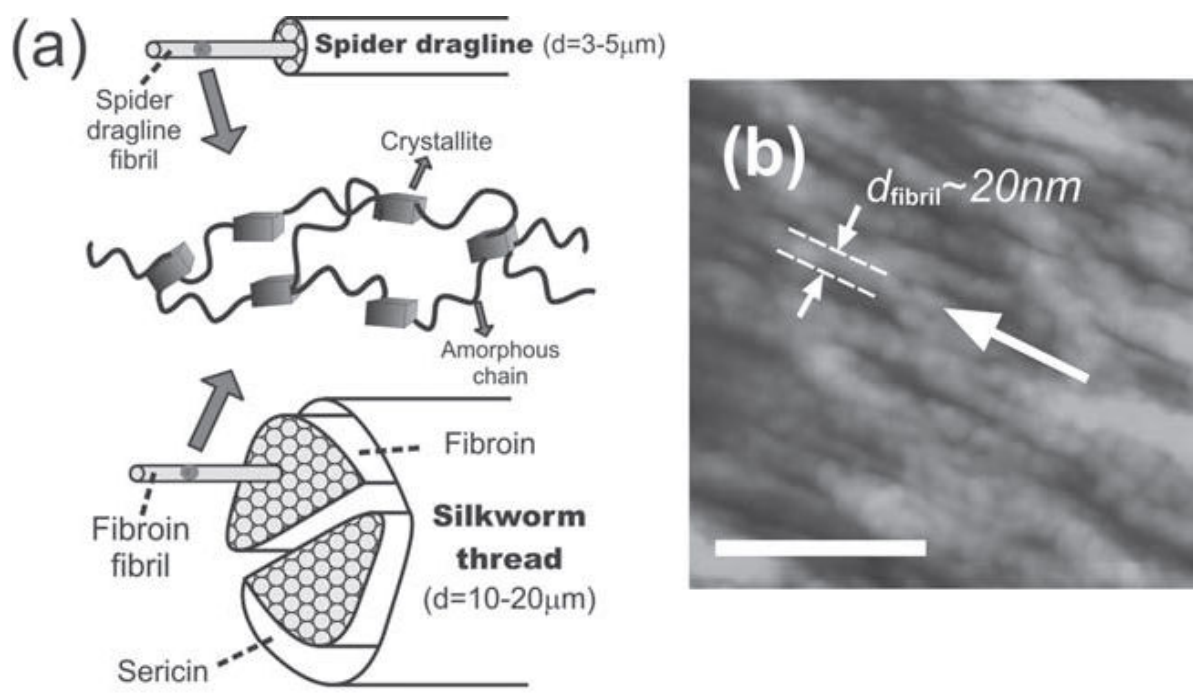

Figure 5. (a) The hierarchical structure of spider dragline and silkworm silk fiber. Both spider dragline and fibroin are composed of numerous minute fibrils, which are separated into crystalline and amorphous segments. (b) The minute fibrils in silkworm B. mori silk as revealed in an AFM image (scale bar: $150 \mathrm{~nm}$ ). The silk fiber direction is indicated by the arrow. (Adapted with permission from Ref. [81]. Copyright 2011, WILEY-VCH.)

$\mathrm{D}_{2} \mathrm{O}$-inaccessible $\beta$-sheets are associated with crystallites, while $\mathrm{D}_{2} \mathrm{O}$-accessible ones are composed of amorphous domains and interphase $\beta$-sheets [82-84]. In the case of spider dragline silk, crystalline component larger in size and poorer in orientation are detectable beside the $\sim 2 \mathrm{~nm}$ sized $\beta$-sheets crystallite that are commonly observed $[69,87,88]$. These observations of larger ordered regions have been explained as 'Non Periodic Lattice (NPL)' crystals which form as a result of statistical matches between compatible sequences on adjacent molecular chains. It was revealed that the border where $\beta$-sheet crystallite regions and amorphous domains do not have any discrete phase boundaries. The presence of the interphase has also been deduced from STXM studies on Nephila dragline silk. It indicates that highly oriented and unoriented domains are surrounded by a moderately oriented matrix [85]. In summary, there is ongoing debate on the molecular structure of silk at the nanoscopic level.

\subsection{The physical (mechanical) properties of silk fibers}

Spider silk and B. mori silk feature unique physical properties - such as superior mechanical properties in terms of toughness (the amount of energy absorbed before breakage) (Table 1). So far, the maximum strength of spider dragline silk (dragline of Caerostris darwini) up to 1.7 $\mathrm{GPa}$, which exceeds that of steel (1.5 GPa), is in the range of high-tech materials [1]. Due to its great extensibility, spider dragline silks have three times of toughness of man-made synthetic fibers like Kevlar 49 [3, 89]. Typical B. mori silk is presumed to be weaker and less extensible than spider dragline silk. However, when forcibly silking from immobilized silkworms 
artificially at certain spinning speed, the mechanical properties of the specific B. mori silk have greatly improved to a level that is comparable the toughest spider silk [4].

The mechanical properties of silk fibers can be described by stress-strain curve profiles, which are generated by stretching the fibers at a specific strain rate. The stress is expressed as force per cross-sectional area and the strain is defined as a normalized extensibility. Typical stressstrain curves for B. mori silkworm silk and spider dragline silk show both elastic behavior followed by plastic deformation [90]. The linear portion of the curve, up to the yield point, is the elastic region. The slope is defined as Young's modulus [91], a measure of the stiffness of the fiber. After the yield point, the fiber buffers the plastic deformation and the stress-strain profiles are subjected to sudden slope changes. This behavior indicates that major structural transition from rubberlike to glassy state occurs in the fiber [92-94]. These characteristics have driven scientists to explore the structural origin of the high-performance silk fiber, with the goal of obtaining templates for designing novel materials with comparable properties.

\subsection{The structure-property relationship of silk fibers}

Evidently, the attractive macroscopic mechanical properties of silk fiber can be ascribed to the structural effects. Most of the attention has focused on the nanometer scale: predominantly, primary and secondary structure, as well as organization and arrangement of protein molecules. In terms of primary structure of silk proteins, amino acid composition, sequential order and the number of the motifs in each module are important for the mechanical properties of the final fibers. For example, the primary structure of Antheraea pernyi (A. pernyi) silk fibroin produced by the 'wild' silkworm, especially the motif, is more like that of major ampullate spidroins than that of B. mori fibroin $[34,95]$. It has been found that such 'wild' silkworm silk displays similar mechanical properties as spider dragline silk [96]. In addition, six novel silk proteins from Mygalomorphae (terantulas) do not possess high tensile strength and elasticity, due to the absence of the four motifs found in major ampullate spidroins [97]. Several studies have tried to establish correlations between specific peptide segments and the mechanical functions of the silk fibers [81, 89, 96, 98-100]. For example, glycine and proline play important specific roles in silk, as they modulate the backbone hydration and conformational order of peptides to govern the behavior of the fibers [101]. The proline-containing motif, GPGXX, was hypothesized to account for the elasticity of silk [102]. However, the primary structure of silk proteins alone does not explain the properties of silk fibers. With merely the protein of the right primary structure, the artificial spun silk fiber is far inferior to the native one [103].

The mechanical properties of silk fibers, also depend crucially on spinning conductions, such as humidity, temperature, and reeling speed, and so on $[19,104]$. Variations in crystallinity and alignment can be found within the silk fiber due to variations in reeling speed of the collected sample. These variations have been mapped to mechanical properties by affecting the formation of the $\beta$-sheet crystals. As reeling speed is increased, the content of $\beta$-sheet structures rise in silk, with increasing orientation of both crystalline and amorphous fractions $[105,106]$. Additionally, the tensile properties (the breaking stress and modulus) of silk fibers increase while breaking strain decreases [4, 19, 107]. It has also shown that reducing the crystal size by increasing the reeling speed has a significant influence on the toughness and ultimate 
strength of the fiber [19]. Recently, Buehler et al. investigated $\beta$-sheet nanocrystals using the sequence from B. mori silk as a model system. They examined the key mechanical parameters of the silk $\beta$-sheet nanocrystals as a function of size. It concluded that small nanocrystals are predominantly loaded in uniform shear so that the hydrogen bonds in $\beta$-sheet strands break by means of stick-slip motion with enhanced energy dissipation and leading to greater stiffness and fracture resistance of silk [108]. Molecular models of silk protein $\beta$-sheet crystals with variation in their $\beta$-strand length were mechanically tested in molecular dynamics simulations. It was found that $\beta$-strands of around eight residues in length were optimal [109]. In summary, primary structure and spinning conditions both contribute to the observed structures higher up the hierarchy associated with the mechanical properties of the silk fiber.

Modern analytical technologies and tools have steadily contributed to the progress in experimental studies of the structure of silk fibers, as described above. However, it is still no consensus on the hierarchical structure of silk at the nanometer scale. Some models have been proposed to interpret the structure-property relationship of silk fibers. The first such model was Termonia's early model [64]. The model hypothesized that silk is a hydrogen-bonded amorphous phase with embedded stiff crystal domains acting as multifunctional cross-links and creating a thin layer of high modulus in the amorphous regions. The stiff hydrogen bonds are first broken to give the fiber its high initial modulus. Meanwhile, it allows the dynamic rubber phase to redistribute the deformation field for prediction of the nonlinear large strain deformation. The simulated properties based on the theoretical model properly reproduce the combination of high initial modulus, strength and toughness of dragline silk fiber. However, in this model, a theoretical modulus of $160 \mathrm{GPa}$ for rigid $\beta$-sheets crystals, assuming fully extended crystals, is much higher than the moduli for $\beta$-sheets crystals obtained from experiments and molecular dynamic simulation [110-112]. Porter and Vollrath et al. includes morphological parameters by simplifying complex structural arrangements of silk fiber into ordered and disordered fractions which are best quantified by the number of amide-amide hydrogen bonds between adjacent chains. These fractions can each impart individual attributes to the property profile (such as stiffness and energy dissipation). This model predicts the range of silk tensile properties in good agreement with the experimental observation [56, 113]. Krasnov et al. established a viscoelatic model for B. mori silk in the form of standard threeparameter Maxwell model, where the elastic modulus is split into amorphous and crystalline elastances. Subsequently, the elastic modulus is parallelly connected to the elements standing for the relaxation processes of the amorphous regions which are observed through cyclic tensile stretching measurements on a single silkworm silk fiber. They separated the mechanical properties of the crystalline and amorphous phases, as well as the interplay between mechanical properties and morphology, of silk. The model fits well with the reports of testing experiment [111]. Buehler et al. presented a simple coarse-grained model in which a combination of $\beta$-sheet nanocrystal and semi-amorphous region is modeled by beads connected via multilinear springs in a serial arrangement, representing the fundamental unit building block of the silk fiber. The mechanical behavior of these domains was simulated based on this model and the resulting stress-strain curve displays the characteristic shape observed in silk. It develops a fundamental understanding of silk's mechanics. In general, amorphous regions contribute to the elasticity of the material. The amorphous regions unravel first when silk is 
being stretched, leading to its large extensibility. Conversely, highly ordered, crystalline regions play a major role in determining the strength and stiffness of silks [114].

Multi-scale experimental and simulation analyses are the key to improve our systematic understanding of how structure and properties are linked. The mechanical mechanism at the macroscopic scale, namely, the fibril, including morphology and its consequence for mechanical behavior and the mechanistic interplay with nanostructure of silk, has also been elucidated [115-117]. At the same time, many experiments have been employed to assess the effect of structural changes on the mechanical deformation of silk [118-121]. When mechanical load are applied to the fibers, conformation, reorientation, crystallite size, and some other structural characters are monitored to explain the structure-property relationships.

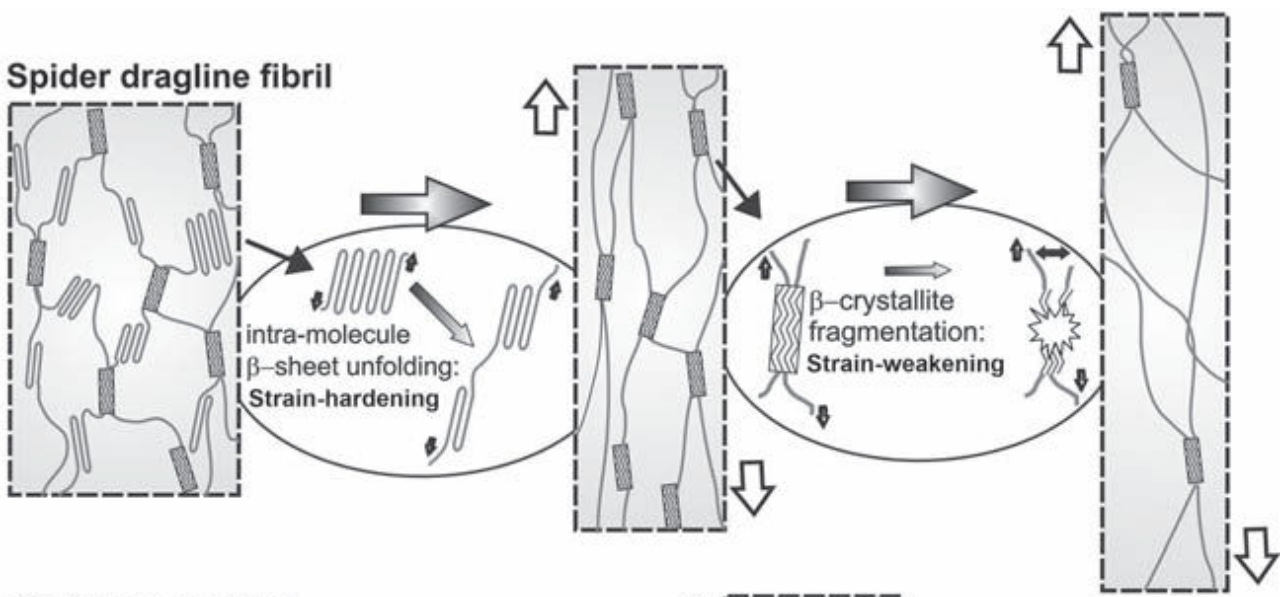

\section{Silkworm silk fibril}

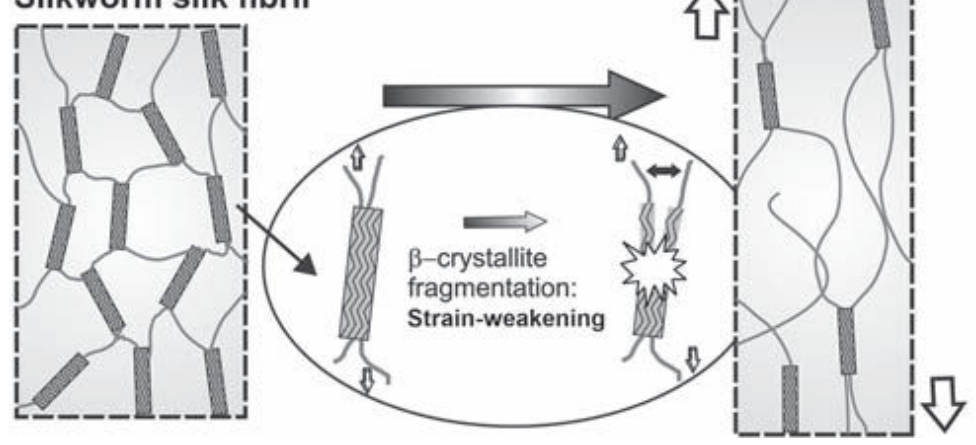

Figure 6. A schematic model demonstrating how the silkworm and spider dragline fibers respond when they are subjected to stretching. There are two components in the alanine-rich regions of spider dragline silk: $\beta$-crystallites and intramolecular $\beta$-sheets. (Adapted with permission from Ref. [81]. Copyright 2011, WILEY-VCH.)

The experimental and computational investigations shown above have explored mechanical properties of B. mori silkworm silks and spider draglines at different structural hierarchies 
from sequence to crystallites to fibrils to fibers, as well as the effect of structural changes on the overall mechanical behavior of silk fibers. In particular, a closer analysis of the mechanical response, spider draglines behave typically the strain-hardening process in the post-yield region [81]. Based on the ' $\beta$-sheet splitting' mechanism [122], the occurrence of strain-hardening in spider dragline as response to the structural factors has been clearly addressed. Spider dragline silk can acquire extra toughness as a strain-hardening material by breaking intramolecular $\beta$-sheets. On the other hand, B. mori silkworm silk has far fewer intramolecular $\beta$-sheets in the amorphous region, therefore it is less extensible and only exhibits strain-weakening after yield point (Figure 6).

Furthermore, unlike B. mori silk and the other types of spider silks, the mechanical properties of spider dragline silks are greatly influenced by water. When an unconstrained dragline silk fiber is immersed in water or comes in contact with a relative humidity greater than $60 \%$, the thread starts to swell radially, doubling in diameter and a shrinking to half of its original length [123]. This process is known as supercontraction, which is another interesting property of spider silk. A number of research groups have used different experimental techniques to understand supercontraction and the underlying mechanisms [124-126]. It is assumed that supercontraction is a result of reorientation of hydrogen bonds within the chains of protein molecules and is accompanied with the release of the prestress [127-130]. Some researchers attributed supercontraction mainly on the proline content of MaSp2 protein. Notably, the content of proline does not correlate with the mechanical performance of spider dragline silk fibers from different species, but influences the mechanical properties of wetted dragline silks $[99,126,131,132]$. Recently, Guan et al. discussed the role of the two MaSp1 and MaSp2 proteins in supercontraction and quantified a contraction of about $13 \%$ maximum, linked to the disordered component of MaSp1 protein. Thus the remaining supercontraction to a total of about $30 \%$ is linked to the intrinsically disordered proline-containing fraction of MaSp2 protein [133]. After supercontraction, the silk is called supercontracted fibers, and are usually to be employed to study the structure-property relationship of silk fiber [123, 134].

\section{Silk protein assembly and silk fiber formation mechanism}

The remarkable mechanical properties of silk fibers have spawned great interests in determination of their origin. Systematic studies of the natural spinning process of silk fibers have shown a highly sophisticated hierarchical process, allowing for the transformation of soluble silk protein into solid fibers with specific mechanical and functional properties. Although much is already known about the characteristics of the silk proteins and silk fibers themselves, the process for silk assembly and spinning into fibers is yet to be resolved. A detailed knowledge of silk fiber formation is critical for the biomimetic production of tough silk-like fibers.

\subsection{Natural spinning process for $B$. mori silk and spider draglines}

In nature, silk proteins are secreted and stored in the glands until they are processed into fibers. Morphological and histological studies demonstrate that the silk glands of B. mori silkworm 
are a pair of tubes and the two tubal glands are connecting before the spinneret. The gland of B. mori silkworm can be divided into three parts: posterior, middle and anterior [135]. The fibrion protein is synthesized and present in a weak gel in the posterior division. The secreted proteins are transported to the middle division, where the sericin is synthesized, accumulating as a shell around the fibroin. Due to the water going out through the cell wall of the gland in the middle division, highly concentrated gel-like fibroin begins to undergo a gel-sol transition and serves as a concentrated protein solution of $30 \mathrm{wt} \%$ [136]. Notably, the highly concentrated liquid protein, often referred to as the spinning dope, displays nematic liquid crystal properties [137-139]. The spinning dope is exposed to the elongational flow and moves forward in the anterior division. The shear force increases along the anterior division and the spinneret, leading to the orientation of the liquid crystallinity. The crystalline spinning dope is converted into a fiber containing water-insoluble silk II. This process is accompanied by extrusion through the spinneret into air, evaporating the residual water. Another remarkable feature of the fiber spinning is the stretching force, which is brought about by the repeated drawing back of the silkworm's head, causing the orientation of protein molecules along with the silk fiber.

The major gland responsible for the dragline silk of Nephila clavipes spider contains the following components: a long tail, a wider sac, named ampulla, and spinning duct approaching the spinneret [140]. Each division of the gland possesses a unique function in fiber formation. For instance, a highly viscous silk protein solution of $~ 50 \%(\mathrm{w} / \mathrm{v})$ is secreted from the A-zone of the gland, which is comprised of the tail and two thirds part of the sac. Further compounds forming the shell of the fiber may arise in the B-zone of the gland, which occupies the rest part of the sac. Like in the B. mori silkworm, the viscosity of the spider's liquid crystalline protein becomes lower and the spinning dope moves forward in the spinning duct where the orientation of liquid crystalline protein into a fiber begins. Due to its tapering, the shear force is increasing along the spinning duct and the stress forces generated in the drawdown process bring the protein molecules into alignment. Hence the protein molecules join together with hydrogen bonds to give the final fiber with anti-parallel $\beta$-sheet structure. As the silk protein molecules aggregate and crystallize, they become more hydrophobic, inducing the loss of water from the surface of the silk fiber [141-143].

\subsection{Silk protein assembly and silk fiber formation mechanism on a structural view}

The formation of a solid fiber from soluble silk proteins is a remarkable process owing to complex biochemical and physical changes. For silk spinning, several assembly models, such as liquid spinning theory [136] and micelle theory [144] have been proposed for the fiber formation, whereas the details remain to be elucidated. In order to understand the mechanisms of silk proteins assembly and fiber formation, the structure of proteins stored in B. mori silkworm gland and the major ampullate gland of spider should be clarified. In vivo, freshly secreted fibroin first adopts silk I (the crystalline form of B. mori silk fibrion found before the spinning process) and random-coil conformation [145]. Silk I is less stable as shown by attempts to study the secondary structure of silk I form using x-ray diffraction, electron diffraction or SS-NMR have caused the silk I to convert to silk II easily. Silk I remains poorly understood. Most investigations on the structure of the silk I form have been based on model building of 
peptides such as (Gly-Ala) $)_{n}[146,147]$. The comparison of these models with limited experimental data, resulting in a number of conflicting models describing the structure of silk I. Recently, the structure of silk I has been proposed as a repeated $\beta$-turn type II-like structure $[148,149]$. The secreted dragline proteins are mainly natively unfolded within the gland and consist of random-coil and polyproline-II with helix-like structure [150-152]. There is evidence indicates that the polyalanine motifs form polyproline-II with a helix-like structure. Particularly, the polyproline-II conformation may be important for maintaining the highly concentrated spinning dope, since the extended polyproline-II structure could prevent the formation of intramolecular hydrogen bonds. Additionally, the polyproline-II helix in spider fibroin favors transforming into a $\beta$-sheet structure due to their similarity of dihedral angles.

It has reported that $B$. mori fibroins and spider spidroins usually show micellar-like structure $[16,144]$ with an amphiphilic sequence, implying short alternating hydrophilic and hydrophobic amino acid stretches flanked by larger hydrophilic terminal regions [153, 154]. The intervening hydrophilic blocks located among the hydrophobic blocks in the protein prevent premature $\beta$-sheet formation, thus maintaining the solubility of the solution. Hence, the silk fiber formation involves shear force inducing the conversion of silk protein with specific structural conformations into $\beta$-sheet structure. This conversion occurs in the spinning ducts followed by drawing down into fibrillar structure. It has shown upon passage through the gland and spinning duct, the proteins encounter remarkable changes in their solvent environment, such as extensional flow, protein concentration, $\mathrm{pH}$ and metal ion concentrations, which are thought to be contributing factors in silk processing and affecting structural conformations $[3,142,155-157]$. The changes include removal of some water, slight acidification. In addition, the concentration of calcium ions $\left(\mathrm{Ca}^{2+}\right)$ are increased as the silk protein flowed through the gland in B. mori. Unlike in the silkworm B. mori, the elemental composition of the silk dope in the spider suggested that $\mathrm{Ca}^{2+}$ ions concentration stayed constant while potassium ions $\left(\mathrm{K}^{+}\right)$ concentration increased. Meanwhile, sodium ions $\left(\mathrm{Na}^{+}\right)$, chlorine ions $\left(\mathrm{Cl}^{-}\right)$are removed from the major ampullate gland.

Experiments made in vitro can provide several relevant insights into the process of silk protein assembly and the formation mechanism of the silk fiber. To unravel the assembly mechanism, the reconstituted/recombinant proteins were applied for fiber assembly under specific condition [158-163]. Jin et al. characterized the change of the supramolecular structure of silk fibroin with a reduction of the $\mathrm{pH}$, which demonstrates the self-assembly of silk fibroin as a function of $\mathrm{pH}$. When the $\mathrm{pH}$ is reduced from 6.8 to 4.8 , a morphological transition of silk fibroin from spherical micelles to nanofibrils and the conformational transition of silk fibroin from random coil to $\beta$-sheet were observed [158]. It may be driven by the stretching entropy effect related to the hydrophobic block in the protein. Shniepp et al. [160] deposited the silk protein solution on mica substrates without and with shearing by spin-coating. Only when shear force was applied during deposition, fibrillar structures were obtained. A microfluidic device was employed in which the ion concentrations and $\mathrm{pH}$ value could be controlled, and simultaneously, physical stress could be applied by channel design [163]. Silk fibers formed after addition of phosphate, application of an elongational flow, and a $\mathrm{pH}$ change from 8 to pH 6. 


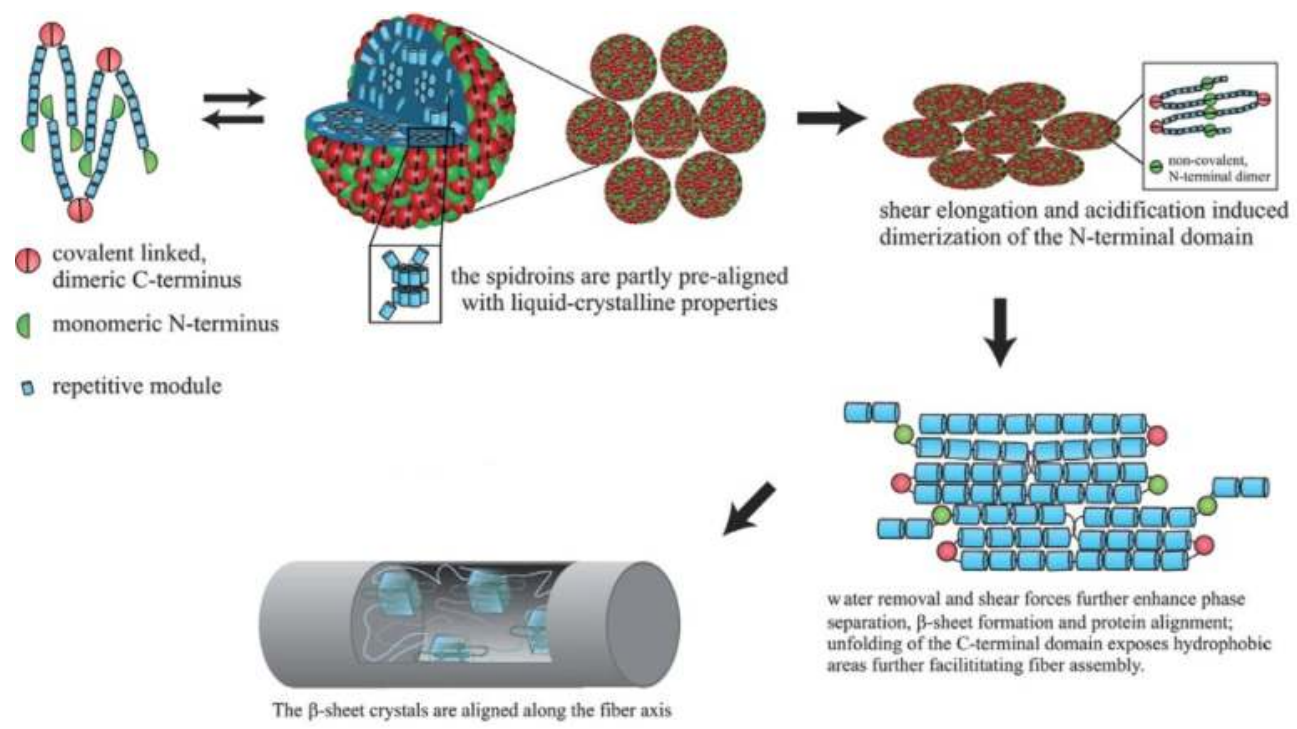

Figure 7. Schematic formation mechanism of the hierarchical assembly from molecular silk fibroin to microfibers. (Reprinted from Ref. [1]. Copyright 2011, with permission from Elsevier.)

Actually, the chemical and mechanical stimuli together are likely to influence the fold of nonrepetitive amino-terminal and carboxy-terminal and the hydrophilic spacers within the hydrophobic core domain [37, 135, 158, 164-166]. Due to the larger hydrophilic blocks at the chain ends of the protein molecules having charged groups, it is possible that they might play an important role in the molecular assembly and conformational transition at a specific $\mathrm{pH}$ through decreased electrostatic repulsion. A significant step towards understanding the effect of the terminal domains in assembly was the determination of atomistic structures of the nonrepetitive terminal regions of MaSp proteins. Kessler and Scheibel's group reported the structure of carboxy-terminal domain of Araneus diadematus ADF 3 by NMR spectroscopy [36]. And Johannson, Knight reported the structures of amino-terminal domain of Euprosthenops australis MaSp1 by X-ray scattering [35]. Interestingly, both terminal domains are mainly composed of $\alpha$-helical barrels but with different folds. The carboxy-terminal domain mediates homodimerization via a disulfide bond [36] and forms a clamp-like structural arrangement. It seems to be implicated in a number of different functions, including control of solubility and fiber formation. The carboxy-terminal domains are able to form supramolecular assemblies resembling micellar-like structure, which is stabilized by the chaotropic ions (Figure 7). The amino-terminal domains are monomeric at $\mathrm{pH} 6.8$ and above [35]. And recent NMR and light scattering studies on the amino-terminal nonrepetitive domain of Latrodectus hesperus confirmed that a combination of $\mathrm{pH}$ and salt concentration controlled the dimerization. The monomer was clearly stabilized at neutral $\mathrm{pH}$ in the presence of salt. While the lower $\mathrm{pH}$ and/ or the reduced salt concentration causes the amino-terminal nonrepetitive domain to dimerize in an antiparallel fashion to create head-to-tail dimmers to dimmers [165]. The $\mathrm{pH}$ dependence 
of silk fiber formation showed that an oligomerization is greatly increased with a drop in $\mathrm{pH}$ at about 6.0, which is triggered by the amino-terminal domain $[35,165]$. The structural changes of the amino-terminal nonrepetitive domains rearrange the position of the core regions within the micellar-like structure, together with mechanical stimuli supports the $\beta$-sheet formation. With the exchange of chaotropic ions for the relatively kosmotropic ions, exposing hydrophobic patches can enhance the assembly process. The amino-terminal and carboxy-terminal domains sense changes in salt, $\mathrm{pH}$, and shear force. And the fine-tuned interplay between these parameters enables the silkworm and spider to efficiently produce a stable very tough fiber under mild conditions

\section{Advanced applications of silk fibers}

Traditionally, silk has been utilized in the construction of textiles. Current research in silk fibers involves their innovative trends and advanced applications. Basically, the rich proportion of essential amino acids in silk fibers indicates high nutritive value, meaning that silk fibroin can be used as a dietary additive [167-169]. Furthermore, the amino acids, glycine, alanine, serine and tyrosine are of vital for nourishing the skin. The crystalline structure of silk protein reflects UV radiation, acting as protective buffer between the skin and environment. The extracts of silk protein are used in soap making, personal care and cosmetic products. The silk protein is also applied to enhance glossy, brightness, and softness of products. In addition, the production of advanced man made super-fibers such as Kevlar involves petrochemical processing, which contributes to pollution. Interest in silk fibers is mainly due to the combination of the mechanical properties and eco friendly way in which they are made. Spider silk fibers have been envisioned to be applied in a variety of technical textiles, including parachute cords, protective clothing and composite materials in aircrafts, which demand high toughness in combination with sleaziness.

Silks are biocompatible, biodegradable and have implant ability, as well as morphologic flexibility. Silk fiber has been used as extremely thin suture for eye or nerve surgery for long history [170]. Nowadays, one attractive application of silk fibers is act as a source of novel biomaterials. Recent progress with processing of silk fibers into various material forms, usually via the formation of the fibroin/spidroin solution, including thread, hydrogels, tubes, sponges, microspheres, particles and films [9, 171], promotes the field of applications for silk fibers in general (Figure 8) [172]. Silk protein can be modified by chemical treatment or used in combination with other materials and the silk-based biomaterials have been transformed for high-technology uses, with promising futures in the fields of biomedicine and material engineering. Numerous studies have demonstrated that fibroin supports cell attachment and proliferation for a variety of cell types [173-178]. Studies have established a potential for silkbased biomaterials use as tissue engineering scaffolds, such as skeletal tissue like bone [179], ligaments [180], and cartilage [181, 182], as well as skin [183], blood vessels [184] and nerve [185]. Silks can be designed and offer another biomedical applications, such as delivery of small molecule drugs, proteins and genes [186]. Silk fibroin possesses remarkable optical properties, such as near-perfect transparency in a visible range. It has been identified as a suitable material 


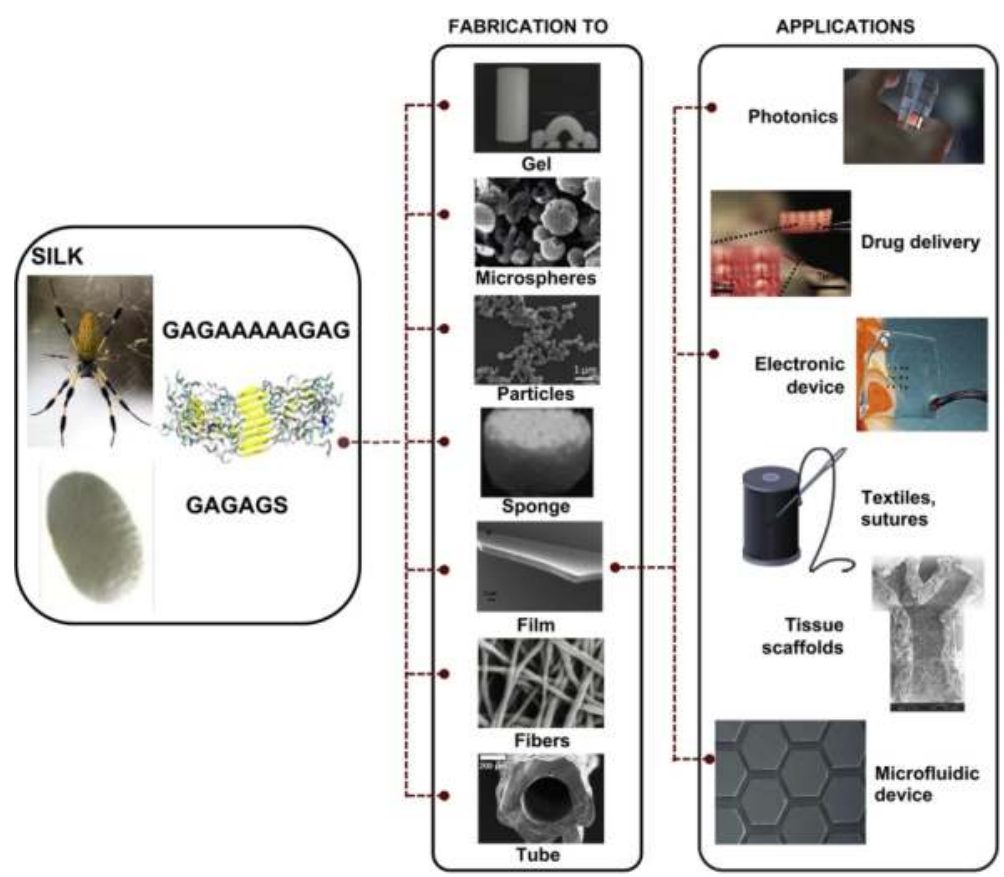

Figure 8. Possible structure and technical applications of the silk fibers. The dotted line shows an example of the versatility of silk and the multiple possible applications. (Figure slightly modified with permission from Ref. [172]. Copyright 2012, Elsevier.)

for the development of biophotonic components [187-189] in biomedical device performing electronics or sensors [190-198]. Surely, these impressive biopolymers are extremely promising for their potential applications in material science and engineering.

\section{Conclusions}

Our review in current chapter concentrated on B. mori silk and spider dragline. It links the physical and mechanical properties of native silk to the molecular make up, assembly and formation process in B. mori silkworm and spider. Over the last decade, there has been considerable progress in understanding the molecular structure of silk, which has inspired us a range of research utilizing the repeating modules of silk in combination with other chemical motifs to develop novel materials. The physical properties of silks highlight the potential for threads to act as high performance fibers. The advances in genetic engineering and gene sequencing enable the production of recombinant proteins in large amount and the exploration of various applications foreseeable in industry. The key point for this area is the development of suitable spinning technologies to reproducibly form threads with properties similar to that of the natural silk. The molecular assembly process of silk has provided us concepts to copy 
and mimic the silkworm's or spider's ways of making and processing silks with tunable properties. Such knowledge is beneficial for further improvement of synthetic polymer-based materials. Combined with the discovery of new bio-inspired materials, the future application space seems more and more broad. As a whole, further development of related yield is underway.

\section{Acknowledgements}

The authors thank the financial support from the National Science Foundation of China (NSFC) under Grant 51073113, 91027039 and the Natural Science Foundation of the Jiangsu Higher Education Institutions of China under Grant 10KJA540046. This work was also supported by the Priority Academic Program Development of Jiangsu Higher Education Institutions (PAPD). We also acknowledge support from the Priority Academic Program Development of Jiangsu Higher Education Institutions (PAPD), Qing Lan Project for Excellent Scientific and Technological Innovation Team of Jiangsu Province (2012) and Project for Jiangsu Scientific and Technological Innovation Team (2013). The author, Xinfang Liu, especially thank the support of the Postdoctoral Science Foundation of Jiangsu province (No. 1201030B).

\section{Author details}

Xinfang Liu and Ke-Qin Zhang*

*Address all correspondence to: kqzhang@suda.edu.cn

National Engineering Laboratory for Modern Silk, College of Textile and Clothing Engineering, Soochow University, Suzhou, China

\section{References}

[1] Eisoldt L., Smith A., Scheibel T. Decoding the secrets of spider silk. Materials Today 2011; 14(3): 80-86.

[2] Craig C L. Evolution of arthropod silks. Annual Review of Entomology 1997; 42: 231267.

[3] Heim M., Keerl D., Scheibel T. Spider silk: From soluble protein to extraordinary fiber. Angewandte Chemie, International Edition 2009; 48(20): 3584-3596.

[4] Shao Z., Vollrath F. Surprising strength of silkworm silk. Nature 2002; 418(15): 741741. 
[5] lizuka E. Silk thread: Mechanism of spinning and its mechanical properties. Journal of Applied Polymer Science: Applied Polymer Symposium 1985; 41: 173-185.

[6] Heslot H. Artifical fibrous proteins: A review. Biochimie 1998; 80(1): 19-31.

[7] Asakura T., Kaplan D L. Silk production and processing. Encyclopedia of Agricultural Science 1994; 4: 1-11.

[8] Lewis R. Unraveling the weave of spider silk. Bioscience 1996; 46(9): 636-638.

[9] Rockwood D N., Preda R C., Yücel T., Wang X Q., Lovett M L., Kaplan D L. Materials fabrication from Bomyx mori silk fibroin. Nature Protocols 2011; 6(10): 1612-1631.

[10] Humenik M., Smith A M., Scheibel T. Recombinant spider silks - Biopolymers with potential for future applications. Polymer 2011; 3(1): 640-661.

[11] Fu C., Shao Z., Fritz V. Animal silks: their structures, properties and artificial production. Chemical Communication 2009; 43: 6515-6529.

[12] Hardy J G., Römer L M., Scheibel T R. Polymeric materials based on silk proteins. Polymer 2008; 49(30): 4309-4327.

[13] Gührs K H., Weisshart K., Grosse F. Lessons from nature - protein fibers. Reviews in Molecular Biotechnology 2000; 74(2): 121-134.

[14] Shen Y., Johnson M A., Martin D C. Microstructural characterization of Bombyx mori silk fibers. Macromolecules 1998; 31(25): 8857-8864.

[15] Li S F., McGhie A J., Tang S L. New internal structure of spider dragline silk revealed by atomic force microscopy. Biophysical Journal 1994; 66(4): 1209-1212.

[16] Oroudjev E., Soares J., Arcdiacono S., Thompson J B., Fossey S A., Hansma H G. Segmented nanofibers of spider dragline silk: Atom force microscopy and single-molecule force spectroscopy. Proceedings of the National Academy of Science of the United States of America 2002; 99(9, suppl.2): 6460-6465.

[17] Augsten K., Muehlig P., Hermann C. Glycoproteins and skin-core structure in Nephila clavipes spider silk observed by light and electron microscopy. Scanning 2000; 22(1): 12-15.

[18] Putthanarat S., Stribeck N., Fossey S A., Eby R K., Adams W W. Investigation of the nanofibrils of silk fibers. Polymer 2000; 41(21): 7735-7747.

[19] Du N., Liu X Y., Narayanan J., Li L., Lim M L M., Li D. Design of superior spider silk: From nanostructure to mechanical properties. Biophysical Journal 2006; 91(12): 45284535.

[20] Padamwar M N., Pawar A P. Silk sericin and its applications: A review. Journal of Scientific \& Industrial Research 2004; 63(4): 323-329. 
[21] Robson R M. Microvoids in Bombyx mori silk. An electron microscope study. International Journal of Biological Macromolecules 1999; 24(2-3): 145-150.

[22] Frische S., Maunsbach A B., Vollrath F. Elongate cavities and skin-core structure in Nephila spider silk observed by electron microscopy. Journal of Microscopy 1998; 189(1): 64-70.

[23] Takei F., Kikuchi Y., Kikuchi A., Mizuno S., Shimura K. Further evidence for importance of the subunit combination of silk fibroin in its efficient secretion from the posterior silk gland cells. The Journal of Cell Biology 1987; 105(1): 175-180.

[24] Tanaka K., Mori K., Mizuno S. Immunological identification of the major disulfidelinked light component of silk fibroin. Journal of Biochemistry (Tokyo) 1993; 114(1): $1-4$.

[25] Tanaka K., Kajiyama N., Ishikura K., Waga S., Kikuchi A., Ohtomo K., Takagi T., Mizuno S. Determination of the site of disulfide linkage between heavy and light chains of silk fibroin produced by Bombyx mori. Biochimica et Biophysica Act (BBA) Protein Structure and Molecular Enzymology 1999; 1432(1): 92-103.

[26] Xu M., Lewis R V. Structure of a protein superfiber: spider dragline silk. Proceedings of the National Academy of Science of the United States of America 1990; 87(18): $7120-7124$.

[27] Hinman M B., Lewis R V. Isolation of a clone encoding a second dragline silk fibroin. Nephila clavipes dragline silk is a two-protein fiber. The Journal of Biological Chemistry 1992; 267(27): 19320-19324.

[28] Beckwitt R., Arcidiacono S. Sequence conservation in the C-terminal region of spider silk proteins (spidroin) from Nephila clavipes (Tetragnathidae) and Araneus bicentenarius (Araneidae). The Journal of Biological Chemistry 1994; 269(9): 6661-6663.

[29] Sponner A., Vater W., Rommerskirch W., Vollrath F., Unger E., Grosse F., Weisshart $\mathrm{K}$. The conserved C-termini contribute to the properties of spider silk fibroins. Biochemical and Biophysical Research Communications 2005; 338(2): 897-902.

[30] Eisoldt L., Thamm C., Scheibel T. The role of terminal domains during storage and assembly of spider silk proteins. Biopolymers 2012; 97(6): 355-361.

[31] Rising A., Hjälm G., Engström W., Johansson J. N-terminal nonrepetitive domain common to dragline, flagelliform, and cylindriform spider silk proteins. Biomacromolecules 2006; 7(11): 3120-3124.

[32] Motriuk-Smith D., Smith A., Hayashi C Y., Lewis R V. Analysis of the conserved Nterminal domains in major ampullate spider silk proteins. Biomacromolecules 2005; 6(6): 3152-3159. 
[33] Zhou C Z., Confalonieri F., Jacquet M., Perasso R., Li Z G., Janin J. Silk fibroin: structural implications of a remarkable amino acid sequence. Proteins: Structure, Function, and Genetics 2001; 44(2): 119-122.

[34] Zhou C Z., Confalonieri F., Medina N., Zivanovic Y., Esnault C., Yang T., Jacquet M., Janin J., Duguet M., Perasso R., Li Z G. Fine organization of Bombyx mori fibroin heavy chain gene. Nucleic Acid Research 2000; 28(12): 2413-2419.

[35] Askarieh G., Hedhammar M., Nordling K., Saenz A., Casals C., Rising A., Johansson J., Knight S D. Self-assembly of spider silk proteins is controlled by a $\mathrm{pH}$-sensitive relay. Nature 2010; 465(13): 236-238.

[36] Hagn F., Eisoldt L., Hardy J G., Vendrely C., Coles M., Scheibel T., Kessler, H. A conserved spider silk domain acts as a molecular switch that controls fibre assembly. Nature 2010; 465(13): 239-242.

[37] He Y X., Zhang N N., Li W F., Jia N., Chen B Y., Zhou K., Zhang J., Chen Y., Zhou C Z. N-terminal domain of Bombyx mori fibroin mediates the assembly of silk in response to pH decrease. Journal of Molecular Biology 2012; 418(3-4): 197-207.

[38] Hagn F. A structural view on spider silk proteins and their role in fiber assembly. Journal of Peptide Science 2012; 18(6): 357-365.

[39] Ittah S., Cohen S., Garty S., Cohn D., Gat U. An essential role for the C-terminal domain of a dragline spider silk protein in directing fiber formation. Biomacromolecules 2006; 7(6): 1790-1795.

[40] Bini E., Knight D P., Kaplan D L. Mapping domain structures in silks from insects and spiders related to protein assembly. Journal of Molecular Biology 2004; 335(1-2): 27-40.

[41] Simmons A., Ray E., Jelinski L. W. Solid-state ${ }^{13} \mathrm{C}$ NMR of Nephila clavipes dragline silk establishes structure and identity of crystalline regions. Macromolecules 1994; 27(18): 5235-5237.

[42] Asakura T., Yao J. ${ }^{13} \mathrm{C}$ CP/MAS NMR study on structural heterogeneity in Bombyx mori silk fiber and their generation by stretching. Protein Science 2002; 11(11): 27062713.

[43] Boulet-Audet M., Lefèvre T., Buffeteau T., Pézolet M. Attenuated total reflection infrared spectroscopy: An efficient technique to quantitatively determine the orientation and conformation of proteins in single silk fibers. Applied Spectroscopy 2008; 62(9): 956-962.

[44] Holland G P., Creager M S., Jenkins J E., Lewis R V., Yarger J L. Determining secondary structure in spider dragline silk by carbon-carbon correlation solid-state NMR spectroscopy. Journal of the American Chemistry Society 2008; 130(30): 9871-9877.

[45] Colomban P., Dinh H M., Riand J., Prinsloo L C., Mauchamp B. Nanomechanics of single silkworm and spider fibres: a Raman and micro-mechanical in situ study of the 
conformation change with stress. Journal of Raman Spectroscopy 2008; 39(12): 1749_ 1764.

[46] Lefèvre T., Rousseau M E., Pézolet M. Protein secondary structure and orientation in silk as revealed by Raman spectromicroscopy. Biophysical Journal 2007; 92(8): 28852895.

[47] Holland G P., Jenkins J E., Creager M S., Lewis R V., Yarger J L. Quantifying the fraction of glycine and alanine in $\beta$-sheet and helical conformations in spider dragline silk using solid-state NMR. Chemical Communication 2008; 43: 5568-5570.

[48] Jenkins J E., Creager M S., Lewis R V., Holland G P., Yarger J L. Quantitative correlation between the protein primary sequences and secondary structures in spider dragline silks. Biomacromolecules 2010; 11(1): 192-200.

[49] Ling S., Qi Z., Knight D P., Shao Z., Chen X. Synchrotron FTIR microspectroscopy of single natural silk fibers. Biomacromolecules 2011; 12(9): 3344-3349.

[50] Dicko C., Knight D., Kenney J M., Vollrath F. Structural conformation of spidroin in solution: A synchrotron radiation circular dichroism study. Biomacromolecules 2004; 5(3): 758-767.

[51] Lefèvre T., Paquet-Mercier F., Rioux-Dubé J F., Pézolet M. Structure of silk by Raman spectromicroscopy: From the spinning glands to the fibers. Biopolymers 2012; 97(6): 322-336.

[52] Kaplan D.; Adams W W., Farmer B., Viney C., editors. Silk polymers: materials science and biotechnology. American Chemical Society Symposium Series 1994.

[53] Marsh R E., Corey R B., Pauling L. An investigation of the structure of silk fibroin. Biochimica et Biophysica Acta 1955; 16: 1-34.

[54] Warwicker J O. Comparative studies of fibroins: II. The crystal structures of various fibroins. Journal of Molecular Biology 1960; 2(6): 350-362.

[55] Dekker M. In: Porter D. (ed.) Group interaction modeling of polymer properties. New York. 1995. P499.

[56] Porter D., Vollrath F., Shao Z. Predicting the mechanical properties of spider silk as a model nanostructured polymer. The European Physical Journal E 2005; 16(2): 199_ 206.

[57] Rousseau M E., Lefèvre T., Beaulieu L., Asakura L., Pézolet M. Study of protein conformation and orientation in silkworm and spider silk fibers using Raman microspectroscopy. Biomacromolecules 2004; 5(6): 2247-2257.

[58] Krimm S., Bandekar J. Vibrational Spectroscopy and conformation of peptides, polypeptides, and proteins. Advances in Protein Chemistry 1986; 38: 181-364. 
[59] Dong J., Wan Z., Popov M., Carey P R., Weiss M. A. Insulin assembly damps conformational fluctuations: Raman analysis of amide I line-widths in native states and fibrils. Journal of Molecular Biology 2003; 330(2): 431-442.

[60] Zheng S., Li G., Yao W., Yu T. Raman spectroscopic investigation of the denaturation process of silk fibroin. Applied Spectroscopy 1989; 43(7): 1269-1272.

[61] Simmons A H., Michal C A., Jelinski L W. Molecular orientation and two-component nature of the crystalline fraction of spider dragline silk. Science 1996; 271(5245): 8487.

[62] Takahashi Y. Crystal structure of silk of Bombyx mori. In: Kaplan D.; Adams W W., Farmer B., Viney C. (eds.) Silk polymers: materials science and biotechnology. American Chemical Society Symposium Series 1994. 544: P168-175.

[63] Drummy L F., Farmer B L., Naik R R. Correlation of the $\beta$-sheet crystal size in silk fibers with the protein amino acid sequence. Soft Matter 2007; 3(7): 877-882.

[64] Termonia Y. Molecular modeling of spider silk elasticity. Macromolecules 1994; 27(25): 7378-7381.

[65] Kümmerlen J., van Beek J D., Vollrath F., Meier B H. Local structure in spider dragline silk investigated by two-dimensional spin-diffusion nuclear magnetic resonance. Macromolecules 1996; 29(8): 2920-2928.

[66] Becker M A., Tuross N. Initial degradation changes found in Bombyx mori silk fibroin. In: Kaplan D.; Adams W W., Farmer B., Viney C. (eds.) Silk polymers: materials science and biotechnology. American Chemical Society Symposium Series 1994. 544: P252-269.

[67] Yang Z., Grubb D T., Jelinski L W. Small-angle X-ray scattering of spider dragline silk. Macromolecules 1997; 30(26): 8254-8261.

[68] Plaza G R., Pérez-Rigueiro J., Riekel C., Perea G B., Agulló-Rueda F., Burghammer M., Guinea G V., Elices M. Relationship between microstructure and mechanical properties in spider silk fibers: identification of two regimes in the microstructural changes. Soft Matter 2012; 8(22): 6015-6020.

[69] Sampath S., Isdebski T., Jenkins J E., Ayon J V., Henning R W., Orgel J P R O., Antipoa O., Yarger J L. X-ray diffraction study of nanocrystalline and amorphous structure within major and minor ampullate dragline spider silks. Soft Matter 2012; 8(25): 6713-6722.

[70] Grubb D T., Jelinski L W. Fiber morphology of spider silk: The effects of tensile deformation. Macromolecules 1997; 30(10): 2860-2867.

[71] Grubb D T., Ji G. Molecular chain orientation in supercontracted and re-extended spider silk. International Journal of Biological Macromolecules 1999; 24(2-3): 203-210. 
[72] Cruz D H., Rousseau M E., West M M., Pézolet M., Hitchcock A P. Quantitative mapping of the orientation of fibroin $\beta$-sheets in B. mori cocoon fibers by scanning transmission X-ray microscopy. Biomacromolecules 2006; 7(3): 836-843.

[73] van Beek J D., Hess S., Vollrath F., Meier B H. The molecular structure of spider dragline silk: Folding and orientation of the protein backbone. Proceedings of the National Academy of Science of the United States of America 2002; 99(16): 10266-10271.

[74] Marcotte I., van Beek J D., Meier B H. Molecular disorder and structure of spider dragline silk investigated by two-dimensional solid-state NMR spectroscopy. Macromolecules 2007; 40(6): 1995-2001.

[75] Asakura T., Yao J., Yamane T., Umemura K., Ulrich A S. Heterogeneous structure of silk fibers from Bombyx mori resolved by ${ }^{13} \mathrm{C}$ solid-state NMR spectroscopy. Journal of the American Chemical Society 2002; 124(30): 8794-8795.

[76] Gosline J M., Denny M W., DeMont M E. Spider silk as rubber. Nature 1984; 309(5968): 551-552.

[77] Gatesy J., Hayashi C., Motriuk D., Woods J., Lewis R. Extreme diversity, conservation, and convergence of spider silk fibroin sequence. Science 2001; 291(5513): 26032605 .

[78] Ma B Y., Nussinov R. Molecular dynamics simulations of alanine rich $\beta$-sheet oligomers: Insight into amyloid formation. Protein Science 2002; 11(10): 2335-2350.

[79] Keten S., Buehler M J. Atomistic model of the spider silk nanostructure. Applied Physics Letters 2010; 96(15): 153701-153703.

[80] Keten S., Buehler M J. Nanostructure and molecular mechanics of spider dragline silk protein assemblies. Journal of the Royal Society Interface 2010; 7(53): 1709-1721.

[81] Du N., Yang Z., Liu X Y., Li Y., Xu H Y. Structural origin of the strain-hardening of spider silk. Advanced Functional Materials 2011; 21(4): 772-778.

[82] Li X., Eles P T., Michal C A. Water permeability of spider dragline silk. Biomacromolecules 2009; 10(5): 1270-1275.

[83] Ene R., Papadopoulos P., Kremer F. Partial deuteration probing structural changes in supercontracted spider silk. Polymer 2010; 51(21): 4784-4789.

[84] Paquet-Mercier F., Lefèvre T., Auger M., Pézolet M. Evidence by infrared spectroscopy of the presence of two type of $\beta$-sheets in major ampullate spider silk and silkworm silk. Soft Matter 2013; 9(1): 208-215.

[85] Rousseau M E., Cruz D H., West M M., Hitchcock A P., Pézolet M. Nephila clavipes spider dragline silk microstructure studies by scanning transmission X-ray microscopy. Journal of the American Chemical Society 2007; 129(13): 3897-3905. 
[86] Fossey S A., Tripathy S. Atomistic modeling of interphases in spider silk fibers. International Journal of Biological Macromolecules 1999; 24(2-3): 119-125.

[87] Thiel B L., Guess K B., Viney C. Non-periodic lattice crystals in the hierarchical microstructure of spider (major ampullate) silk. Biopolymers 1997; 41(7): 703-719.

[88] Trancik J E., Czernuszka J T., Bell F I., Viney C. Nanostructural features of a spider dragline silk as revealed by electron and X-ray diffraction studies. Polymer 2006; 47(15): 5633-5642.

[89] Swanson B O., Blackledge T A., Beltran J., Hayashi C Y. Variation in the material properties of spider dragline silk across species. Applied Physics A: Materials Science \& Processing 2006; 82(2): 213-218.

[90] Sirichaisit J., Brookes V L., Young R J., Vollrath F. Analysis of structure/property relationships in silkworm (Bombyx mori) and spider dragline (Nephila edulis) silks using Raman spectroscopy. Biomacromolecules 2003; 4(2): 387-394.

[91] Denny M. The physical properties of spider's silk and their role in the design of orbwebs. The Journal of Experimental Biology 1976; 65(2): 483-506.

[92] Gosline J M., Guerette P A., Ortlepp C S., Savage K N. The mechanical design of spider silks: From fibroin sequence to mechanical function. The Journal of Experimental Biology 1999; 202(23): 3295-3303.

[93] Hu X., Vasanthavada K., Kohler K., McNary S., Moore A M F., Vierra C A. Molecular mechanisms of spider silk. Cellular and Molecular Life Sciences 2006; 63(17): 19861999.

[94] Ko F K., Jovicic J. Modeling of mechanical properties and structural design of spider web. Biomacromolecules 2004; 5(3): 780-785.

[95] Sezutsu H., Yukuhiro K. Dynamic rearrangement within the Antheraea pernyi silk fibroin gene is associated with four types of repetitive units. Journal of Molecular Evolution 2000; 51(4): 329-338.

[96] Fu C., Porter D., Chen X., Vollrath F., Shao Z. Understanding the mechanical properties of Antheraea pernyi silk - From primary structure to condensed structure of the protein. Advanced Functional Materials 2011; 21(4): 729-737.

[97] Garb J E., Dimauro T., Lewis R V., Hayashi C Y. Expansion and intragenic homogenization of spider silk since the triassic: Evidence from mygalomorphae (tarantulas and their kin) spidroins. Molecular Biology and Evolution 2007; 24(11): 2454-2464.

[98] Brooks A E., Steinkraus H B., Nelson S R., Lewis R V. An investigation of the divergence of major ampullate silk fibers from Nephila clavipes and Argiope aurantia. Biomacromolecules 2005; 6(6): 3095-3099.

[99] Liu Y., Sponner A., Porter D., Vollrath F. Proline and processing of spider silks. Biomacromolecules 2008; 9(1): 116-121. 
[100] Brooks A E., Stricker S M., Joshi S B., Kamerzell T J., Middaugh C R., Lewis R V. Properties of synthetic spider silk fibers based on Argiope aurantia MaSp2. Biomacromolecules 2008; 9(6): 1506-1510.

[101] Rauscher S., Baud S., Miao M., Keeley F., Pomes R. Proline and glycine control protein self-organization into elastomeric or amyloid fibrils. Structure 2006; 14(11): 16671676.

[102] Hayashi C Y., Shipley N H., Lewis R V. Hypotheses that correlate the sequence, structure, and mechanical properties of spider silk proteins. International Journal of Biological Macromolecules 1999; 24(2-3): 271-275.

[103] Shao Z., Vollrath F., Yang Y., Thøgersen H C. Structure and behavior of regenerated spider silk. Macromolecules 2003; 36(4): 1157-1161.

[104] Lee S M., Pippel E., Göesele U., Dresbach C., Qin Y., Chandran C V., Bräeuniger T., Hause G., Knez M. Greatly increased toughness of infiltrated spider silk. Science 2009; 324(5926): 488-492.

[105] Riekel C., Müller M. In situ X-ray diffraction during forced silking of spider silk. Macromolecules 1999; 32(13): 4464-4466.

[106] Riekel C., Vollrath F. Spider silk fibre extrusion: combined wide-and small-angle Xray microdiffraction experiments. International Journal of Biological Macromolecules. 2001; 29(3): 203-210.

[107] Khan M R., Morikawa H., Gotoh Y., Miura M., Ming Z., Sato Y., Iwasa M. Structural characteristics and properties of Bombyx mori silk fiber obtained by different artificial forcibly silking speeds. Internation Journal of Biological Macromolecules 2008; 42(3): 264-270.

[108] Keten S., Xu Z., Ihle B., Buehler M J. Nanoconfinement controls stiffness, strength and mechanical toughness of $\beta$-sheet crystals in silk. Nature Materials 2010; 9(4): 359 367.

[109] Xiao S., Stacklies W., Debes C., Gräter F. Force distribution determines optimal length of $\beta$-sheet crystals for mechanical robustness. Soft Matter 2011; 7(4): 13081311.

[110] Sinsawat A., Putthanarat S., Magoshi Y., Pachter R., Eby R K. X-ray diffraction and computational studies of the modulus of silk (Bombyx mori). Polymer 2002; 43(4): 1323-1330.

[111] Krasnov I., Diddens I., Hauptmann N., Helms G., Ogurreck M., Seydel T., Funari S S., Muller M. Mechanical properties of silk: Interplay of deformation on macroscopic and molecular length scales. Physical Review Letters 2008; 100(4): 048104/1-048104/4.

[112] Sinsawat A., Putthanarat S., Magoshi Y., Pachter R., Eby R K. The crystal modulus of silk (Bombyx mori). Polymer 2003; 44(3): 909-910. 
[113] Vollrath F., Porter D. Spider silk as a model biomaterial. Applied Physics A: Materials Science \& Processing 2006; 82(2): 205-212.

[114] Nova A., Keten S., Pugno N M., Redaelli A., Buehler M J. Molecular and nanostructural mechanisms of deformation, strength and toughness of spider silk fibrils. Nano Letters 2010; 10(7): 2626-2634.

[115] Papadopoulos P., Sölter J., Kremer F. Hierarchies in the structural organization of spider silk - a quantitative model. Colloid and Polymer Science 2009; 287(2): 231-236.

[116] Giesa T., Arslan M., Pugno N M., Buehler M J. Nanoconfinement of spider silk fibrils begets superior strength, extensibility, and toughness. Nano Letters 2011; 11(11): 5038-5046.

[117] Brown C P., Harnegea C., Gill H S., Price A J., Traversa E., Licoccia S., Rosei F. Rough fibrils provide a toughening mechanism in biological fibers. ACS Nano 2012; 6(3): 1961-1969.

[118] Lefèvre T., Paquet-Mercier F., Lesage S., Rousseau M E., Bédard S., Pézolet M. Study by Raman spectromicroscopy of the effect of tensile deformation on the molecular structure of Bombyx mori silk. Vibrational Spectroscopy 2009; 51(1): 136-141.

[119] Eles P T., Michal C A. A DECODER NMR study of backbone orientation in Nephila clavipes dragline silk under varying strain and draw rate. Biomacromolecules 2004; 5(3): 661-665.

[120] Seydel T., Kölln K., Krasnov I., Diddens I., Hauptmann N., Helms G., Ogurreck M., Kang S G., Koza M M., Müller M. Silkworm silk under tensile strain investigated by synchrotron X-ray diffraction and neutron spectroscopy. Macromolecules 2007, 40(4): 1035-1042.

[121] Brookes V L., Young R J., Vollrath F J. Deformation micromechanics of spider silk. Journal of Materials Science 2008; 43(10): 3728-3732.

[122] Wu X., Liu X Y., Du N., Xu G., Li B. Unraveled mechanism in silk engineering: Fast reeling induced silk toughening. Applied Physics Letters 2009; 95: 093703/1093703/4.

[123] Jelinski L W., Blye A., Liivak O., Michal C., LaVerde G., Seidel A., Shah N., Yang Z. Orientation, structure, wet-spinning, and molecular basis for supercontraction of spider dragline silk. International Journal of Biological Macromolecules 1999; 24(2-3): 197-201.

[124] Holland G P., Jenkins J E., Creager M S., Lewis R V., Yarger J L. Solid-state NMR investigation of major and minor ampullate spider silk in the native and hydrated states. Biomacromolecules 2008; 9(2): 651-657.

[125] Shao Z., Vollrath F., Sirichaisit J., Young R J. Analysis of spider silk in native and supercontracted states using Raman spectroscopy. Polymer 1999; 40(10): 2493-2500. 
[126] Savage K N., Gosline J M. The effect of proline on the network structure of major ampullate silks as inferred from their mechanical and optical properties. The Journal of Experimental Biology 2008; 211(12): 1937-1947.

[127] Liu Y., Shao Z., Vollrath F. Relationships between supercontraction and mechanical properties of spider silk. Nature Materials 2005; 4(12): 901-905.

[128] Bell F I., McEwen I J., Viney C. Supercontraction stress in wet spider dragline. Nature 2002; 416(6876): 37-37.

[129] Papadopoulos P., Ene R., Weidner I., Kremer F. Similarities in the structural organization of major and minor ampullate spider silk. Macromolecular Rapid Communications 2009; 30(9-10): 851-857.

[130] Blackledge T A., Boutry C., Wong S C., Baji A., Dhinojwala A., Sahni V., Agnarsson, I. How super is supercontraction? Persistent versus cyclic responses to humidity in spider dragline silk. The Journal of Experimental Biology 2009; 212(13): 1981-1988.

[131] Liu Y., Shao Z., Vollrath F. Elasticity of spider silks. Biomacromolecules 2008; 9(7): 1782-1786.

[132] Boutry C., Blackledge T A. Evolution of supercontraction in spider silk: structure function relationship from tarantulas to orb-weavers. The Journal of Experimental Biology 2010, 213(20): 3505-3514.

[133] Guan J., Vollrath F., Porter D. Two mechanisms for supercontraction in Nephila spider dragline silk. Biomacromolecules 2011; 12(11): 4030-4035.

[134] Glišović A., Vehoff T., Davies R J., Salditt T. Strain dependent structural changes of spider dragline silk. Macromolecules 2008; 41(2): 390-398.

[135] Wong Po Foo C., Bini E., Hensman J., Knight D P., Lewis R V., Kaplan D L. Role of $\mathrm{pH}$ and charge on silk protein assembly in insects and spiders. Applied Physics A: Materials Science and Processing 2006; 82(2): 223-233.

[136] Vollrath F., Knight D. P. Liquid crystalline spinning of spider silk. Nature 2001; 410(6828): 541-548.

[137] Knight D P., Vollrath F. Liquid crystals and flow elongation in a spider's silk production line. Proceedings of the Royal Society B: Biological Science 1999; 266(1418): 519523.

[138] Kerkam K., Viney C., Kaplan D L., Lombardi S. Liquid crystallinity of natural silk secretions. Nature 1991; 349(6310): 596-598.

[139] Willcox P J., Gido S P. Muller W. Kaplan D L. Evidence of a cholesteric liquid crystalline phase in natural silk spinning processes. Macromolecules 1996; 29(15): 51065110. 
[140] Lefevre T, Boudreault S, Cloutier C, Pezolet M. Conformational and orientational transformation of silk proteins in the major ampullate gland of Nephila clavipes spiders. Biomacromolecules 2008; 9(9): 2399-2407.

[141] Vollrath F., Knight D P. Structure and function of the silk production pathway in the spider Nephila edulis. International Journal of Biological Macromolecules 1999; 24(2-3): 243-249.

[142] Knight D P., Vollrath F. Changes in element composition along the spinning duct in a Nephila spider. Naturwissenschaften 2001; 88(4): 179-182.

[143] Terry A E., Knight D P., Porter D., Vollrath F. pH induced changes in the rheology of silk fibroin solution from the middle division of Bombyx mori silkworm. Biomacromolecules 2004; 5(3): 768-772.

[144] Jin H J., Kaplan D L. Mechanism of silk processing in insects and spiders. Nature 2003; 424(28): 1057-1061.

[145] Monti P., Taddei P., Freddi G., Asakura T., Tsukada M. Raman spectroscopic characterization of Bombyx mori silk fibroin: Raman spectrum of silk I. Journal of Raman Spectroscopy 2001; 32(2): 103-107.

[146] Asakura T., Yamane T., Nakazawa Y., Kameda T., Ando K. Structure of Bombyx mori silk fibroin before spinning in solid state studied with wide angle $\mathrm{X}$-ray scattering and ${ }^{13} \mathrm{C}$ cross-polarization/magic angle spinning NMR. Biopolymers 2001; 58(5): 521525.

[147] Taddei P., Asakura T., Yao J., Monti P. Raman study of poly(alanine-glycine)-based peptides containing tyrosine, valine, and serine as model for the semicrystalline domains of Bombyx mori silk fibroin. Biopolymers 2004; 75(4): 314-324.

[148] Asakura T., Ashida, J., Yamane T., kameda T., Nakazawa, Y., Ohgo K., Komatsu K. A repeated $\beta$-turn structure in poly(Ala-Gly) as a model for silk I of Bombyx mori silk fibroin studied with two-dimensional spin-diffusion NMR under off magic angle spinning and rotational echo double resonance. Journal of Molecular Biology 2001; 306(2): 291-305.

[149] Asakura T., Ohgo K., Komatsu K., Kanenari M., Okuyama K. Refinement of repeated $\beta$-turn structure for silk I conformation of Bombyx mori silk fibroin using ${ }^{13} \mathrm{C}$ solidstate NMR and X-ray methods. Macromolecules 2005; 38(17): 7397-7403.

[150] Hirijida D H., Do K G., Wong S., Zax D., Jelinski L W. ${ }^{13}$ C NMR of Nephila clavipes major ampullate silk gland. Biophysical Journal 1996; 71(6): 3442-3447.

[151] Hronska M., van Beek J D., Willimason P T F., Vollrath F., Meier B H. NMR characterization of native liquid spider dragline silk from Nephila edulis. Biomacromolecules 2004; 5(3): 834-839.

[152] Lefèvre T., Leclerc J., Rioux-Dubé J F., Buffeteau T., Paquin M C., Rousseau M E., Cloutier I., Auger M., Gagné S M., Boudreault S., Cloutier C., Pézolet M. Conforma- 
tion of spider silk proteins in situ in the intact major ampullate gland and in solution. Biomacromolecules 2007; 8(8): 2342-2344.

[153] Roemer L., Scheibel T. In: Scheibel T. (ed.) Fibrous proteins. Austin: Landes Bioscience; 2008. P137-151.

[154] Exler J H., Hummerich D., Scheibel T. The amphiphilic properties of spider silks are important for spinning. Angewandte Chemie International Edition 2007; 46(19): 3559-3562.

[155] Magoshi J., Magoshi Y., Becker M A., Nakamura S. Biospinning (silk fiber formation, multiple spinning mechanisms). In: Salamone J C. (ed.) Polymeric Materials Encyclopedia. CRC Press: New York. 1996. vol. 1: P667-679.

[156] Vollrath F., Knight D P., Hu X W. Silk production in a spider involves acid bath treatment. Proceedings of the Royal Society B: Biological Science 1998; 265(1398): 817-820.

[157] Hardy J G., Scheibel T R. Silk-inspired polymers and proteins. Biochemical Society Transactions 2009; 37(4): 677-681.

[158] Chen P., Kim H S., Park C Y., Kim H S., Chin I J., Jin H J. pH-triggered transition of silk fibroin from spherical micelles to nanofibrils in water. Macromolecular Research 2008; 16(6): 539-543.

[159] Dicko C., Kenney J M., Knight D., Vollrath F. Transition to a $\beta$-sheet-rich structure in spidroin in vitro: The effects of $\mathrm{pH}$ and cations. Biochemistry 2004; 43(44): 1408014087.

[160] Greving I., Cai M., Vollrath F., Schniepp H C. Shear-induced self-assembly of native silk proteins into fibrils studied by atomic force microscopy. Biomacromolecules 2012; 13(3): 676-682.

[161] Xie F., Zhang H., Shao H., Hu X. Effect of shearing on formation of silk fibers from regenerated Bombyx mori silk fibroin aqueous solution. International Journal of Biological Macromolecules 2006; 38(3-5): 284-288.

[162] Kinahan M E., Filippidi E., Köster S., Hu X., Evans H M., Pfohl T., Kaplan D L., Wong J. Tunable silk: Using microfluidics to fabricate silk fibers with controllable properties. Biomacromolecules 2011; 12(5): 1504-1511.

[163] Rammensee S., Slotta U., Scheibel T., Bausch A R. Assembly mechanism of recombinant spider silk proteins. Proceedings of the National Academy of Science of the United States of America 2008; 105(18): 6590-6595.

[164] Gronau G., Qin Z., Buehler M J. Effect of sodium chloride on the structure and stability of spider silk's N-terminal protein domain. Biomaterial Science 2013; 1(3): 276284. 
[165] Hagn F., Thamm C., Scheibel T., Kessler H. pH-Dependent dimerization and salt-dependent stabilization of the N-terminal domain of spider dragline silk - implications for fiber formation. Angewandte Chemie International Edition 2011; 50(1): 310-313.

[166] Landreh M., Askarieh G., Nordling K., Hedhammar M., Rising A., Casals C., Astorga-Wells J., Alvelius G., Knight S D., Johansson J., Jornvall H., Bergman T. A pH-dependent dimer lock in spider silk protein. Journal of Molecular Biology 2010; 404(2): 328-336.

[167] Dandin S B., Nirmal Kumar S. Bio-medical uses of silk and its derivative. Indian Silk 2006; 45(9):5-8.

[168] Manohar Reddy R. Value addition span of silkworm cocoon - Time for utility optimization. International Journal of Industrial Entomology 2008; 17(1): 109-113.

[169] Michael B. Food management. Proquest Agriculture Journals 2004; 60: 39.

[170] Altman G H., Diaz F., Jakuba C., Calabro T., Horan R L., Chen J., Lu H., Richmond J., Kaplan D L. Silk-based biomaterials. Biomaterials 2003; 24(3): 401-416.

[171] Vepari C., Kaplan D L. Silk as a biomaterial. Progress in Polymer Science 2007; 32(8-9): 991-1007.

[172] Gronau G., Krishnaji S T., Kinahan M E., Giesa T., Wong J Y., Kaplan D L., Buehler M J. A review of combined experimental and computational procedures for assessing biopolymer structure-process-property relationships. Biomaterials 2012; 33(33): 82408255.

[173] Meinel L., Hofmann S., Karageorgiou V., Kirker-Head C., McCool J., Gronowicz G., Zichner L., Langer R., Vunjak-Novakovic G., Kaplan D L. The inflammatory responses to silk films in vitro and in vivo. Biomaterials 2005; 26(2): 147-155.

[174] Gupta M K., Khokhar S K., Phillips D M., Sowards L A., Drummy L F., Kadakia M P., Naik R R. Patterned silk films cast from ionic liquid solubilized fibroin as scaffolds for cell growth. Langmuir 2007; 23(3): 1315-1319.

[175] Servoli E., Maniglio D., Motta A., Predazzer R., Migliaresi C. Surface properties of silk fibroin films and their interaction with fibroblasts. Macromolecular Bioscience 2005; 5(12): 1175-1183.

[176] Min B M., Jeong L., Lee K Y., Park W H. Regenerated silk fibroin nanofibers: water vapor-induced structural changes and their effects on the behavior of normal human cells. Macromolecular Bioscience 2006; 6(4): 285-292.

[177] Unger R E., Wolf M., Peters K., Motta A., Migliaresi C., James Kirkpatrick C. Growth of human cells on a non-woven silk fibroin net: a potential for use in tissue engineering. Biomaterials 2004; 25(6): 1069-1075. 
[178] Jin H J., Chen J., Karageorgiou V., Altman G H., Kaplan D L. Human bone marrow stromal cell responses on electrospun silk fibroin mats. Biomaterials 2004; 25(6): 1039-1047.

[179] Wharram S E., Zhang X., Kaplan D L., McCarthy S P. Electrospun silk material systems for wound healing. Macromolecular Bioscience 2010; 10(3): 246-257.

[180] Fan H., Liu H., Wong E J W., Toh S L., Goh J C H. In vivo study of anterior cruciate ligament regeneration using mesenchymal stem cells and silk scaffold. Biomaterials 2008; 29(23): 3324-3337.

[181] Mandal B B., Priya A S., Kundu S C. Novel silk sericin/gelation 3-D scaffolds and 2-D films: Fabrication and characterization for potential tissue engineering applications. Acta Biomaterialia 2009; 5(8): 3007-3020.

[182] Kasoju N., Bhonde R R., Bora U. Preparation and characterization of Antheraea assama silk fibroin based novel non-woven scaffolds for tissue engineering applications. Journal of Tissue Engineering and Regenerative Medicine 2009; 3(7): 539-552.

[183] Sugihara A., Sugiura K., Morita H., Ninagawa T., Tubouchi K., Tobe R., Izumiya M., Horio T., Abraham N G., Ikehara S. Promotive effects of a silk film on epidermal recovery from full-thickness skin wounds. Proceedings of the Society for Experimental Biology and Medicine 2000; 225(1): 58-64.

[184] Unger R E., Sartoris A., Peters K., Motta A., Migliaresi C., Kunkel M., Bulnheim U., Rychly J., Kirkpatrick C J. Tissue-like self-assembly in cocultures of endothelial cells and osteoblasts and the formation of microcapillary-like structures on three-dimensional porous biomaterials. Biomaterials 2007; 28(27): 3965-3976.

[185] Yang Y., Chen X., Ding F., Zhang P., Liu J., Gu X. Biocompatibility evaluation of silk fibroin with peripheral nerve tissues and cells in vitro. Biomaterials 2007; 28(9): 16431652.

[186] Numata K., Kaplan D L., Silk-based delivery systems of bioactive molecules. Advanced Drug Delivery Reviews 2010; 62(15): 1497-1508.

[187] Lawrence B D., Cronin-Golomb M., Georgakoudi I., Kaplan D L., Omenetto F G. Bioactive silk protein biomaterial systems for optical devices. Biomacromolecules 2008; 9(4): 1214-1220.

[188] Perry H., Gopinath A., Kaplan D L., Negro L D., Omenetto F G. Nano- and micropatterning of optically transparent, mechanically robust, biocompatible silk fibroin films. Advanced Materials 2008; 20(16): 3070-3072.

[189] Omenetto F G., Kaplan D L. A new route for silk. Nature Photonics 2008; 2(11): 641643. 
[190] Amsden J J., Perry H., Boriskina S V., Gopinath A., Kaplan D L., Negro L D., Omenetto F G. Spectral analysis of induced color change on periodically nanopatterned silk films. Optics Express 2009; 17(23): 21271-21279.

[191] Kim D H., Kim Y S., Amsden J., Panilaitis B., Kaplan D L., Omenetto F G., Zakin M R., Rogers J A. Silicon electronics on silk as a path to bioresorbable, implantable devices. Applied Physics Letters 2009; 95(13): 133701/1-133701/3.

[192] Kim D H., Viventi J., Amsden J. J., Xiao J., Vigeland L., Kim Y S., Blanco J A., Panilaitis B., Frechette E. S., Contreras D., Kaplan D L., Omenetto F G., Huang Y., Hwang K C., Zakin M R., Litt B., Rogers J A. Dissolvable films of silk fibroin for ultrathin conformal bio-integrated electronics. Nature Materials 2010; 9(6): 511-517.

[193] Parker S T., Domachuk P., Amsden J., Bressner J., Lewis J A., Kaplan D L., Omenetto F G. Biocompatible silk printed optical waveguides. Advanced Materials 2009; 21(13): 2411-2415.

[194] Kharlampieva E., Kozlovskaya V., Wallet B., Shevchenko V V., Naik R R., Vaia R., Kaplan D L., Tsukruk V V. Co-cross-linking silk matrices with silica nanostructures for robust ultrathin nanocomposities. ACS Nano 2010; 4(12): 7053-7063.

[195] Steven E., Park J G., Paravastu A., Lopes E B., Brooks J S., Englander O., Siegrist T., Kaner P., Alamo R G. Physical characterization of functionalized spider silk: electronic and sensing properties. Science and Technology of Advanced Materials 2011; 12(5): 0055002/1-005002/13.

[196] Huby N., Vié V., Renault A., Beaufils S., Lefèvre T., Paquet-Mercier F., Pézolet M., Bêche B. Native spider silk as a biological optical fiber. Applied Physics Letters 2013; 102(12): 123702/1-123702/3.

[197] Kim S., Mitropoulos A N., Spitzberg J D., Kaplan D L., Omenetto F G. Silk protein based hybrid photonic-plasmatic crystal. Optics Express 2013; 21(7): 8897-8903.

[198] Huang X., Liu G., Wang X. New secrets of spider silk: Exceptionally high thermal conductivity and its abnormal change under stretching. Advanced Materials 2012; 24(11): 1482-1486. 